\title{
ARTículo
}

\section{Reordenando el orden. El reformismo económico del Duque de la Palata (1681-1689)}

\section{Rearranging the order. The economic reformism of Duque de la Palata (1681- 1689)}

\author{
Héctor Palza \\ https://orcid.org/0000-0002-2104-7305 \\ hpalzab@gmail.com \\ Universidad Nacional Mayor de San Marcos
}

\section{RESUMEN}

El dominio español sobre el virreinato peruano experimentó durante la segunda mitad del siglo XVII un declive que trató de ser subsanado. En este contexto, se le encargó al virrey Duque de la Palata desarrollar un plan de acción para apuntalar el sistema de control colonial. En el presente artículo se busca, por un lado, dar a conocer esta actuación, focalizada en el restablecimiento del eje económico vertebrador de la economía colonial y, por otro lado, evidenciar la oposición de los grupos de poder local en el Perú que eran contrarios a las reformas implementadas por este virrey. Esta confrontación dio como resultado el fracaso de dichas reformas, debido a que el desarrollo de los ejes económicos regionales había logrado dañar irreversiblemente al circuito oficial.

Palabras clave: Reformismo económico; economías regionales; Estado metropolitano; ejes económicos; diversificación productiva.

\begin{abstract}
Spanish rule over the Peruvian viceroyalty experienced a decline during the second half of the seventeenth century that it attempted to rectify. In this context, viceroy Duque de la Palata was commissioned to develop an action plan to shore up the colonial control system. This article seeks to show this action, focused on the reestablishment of the economic backbone of the colonial economy. Additionally, the article aims to show how powerful groups opposed the reforms implemented by this viceroy. This confrontation resulted in the failure of those reforms because the development of the regional economic axes had irreversibly damaged the official circuit.
\end{abstract}

Keyword: Economic reformism; regional economies; metropolitan state; economic axes; productive diversification.

(C) Los autores. Este artículo es publicado por ISHRA, Revista del Instituto Seminario de Historia Rural Andina de la Facultad de Ciencias Sociales de la Universidad Nacional Mayor de San Marcos. Este es un artículo de acceso abierto, distribuido bajo los términos de la licencia Creative Commons Atribución 4.0 Internacional (CC BY 4.0) [https://creativecommons.org/licenses/by/4.0/deed.es] que permite el uso, distribución y reproducción en cualquier medio, siempre que la obra original sea debidamente citada de su fuente original. 


\section{Introducción}

El mal manejo de la política metropolitana y la crisis económica que la afectó interrumpió y privó a España de las ingentes cantidades monetarias de plata provenientes del Perú, cuyos montos resultaban insuficientes para atenuar los males del erario real. En este sentido, resultó imprescindible para Madrid restablecer el pleno y absoluto control de estos reinos en la coyuntura específica de la segunda mitad del siglo XVII. A fin de mantener la institucionalidad y el ordenamiento del Estado colonial, la corona le confió esta difícil tarea a Melchor de Navarra y Rocaful, duque de la Palata, un experimentado funcionario de la alta burocracia imperial.

El renovado interés en el papel que desempeñó el duque originó espacios de discusión relacionados con su obra, puntos de vista desarrollados en la interpretación acerca de la política que aplicó este funcionario en el curso del colapso del eje Lima-Potosí. La ampliación de las investigaciones respecto a este tema ha permitido una interpretación más crítica sobre las repercusiones de las políticas implementadas por la Palata, las cuales concentran su atención en la mayoría de estos estudios (Andrien, 1985; Bakewell, 1984; Burkholder y Chandler, 1984; Gonzáles, 2000; Klein, 1994; Lazo, 1992, 1997, 2001; Sempat, 1982; Tandeter, 1992). Carlos Sempat (1982), por ejemplo, plantea que la economía colonial se desarrolló a partir de una economía minera que dio lugar a una economía agraria y de servicios que satisfacía al mercado minero, lo cual va a permitir la formación de núcleos de desarrollo económico regionales con los que los criollos provincianos se empoderan y les hacen frente a sus pares limeños. Esta cercanía también ha sido estudiada por Mark Burkholder y Dewit Chandler (1984), quienes hacen referencia al duque a partir de un análisis que intenta explicar la predominancia de criollos americanos en la Audiencia de Lima desde 1690.

Estos avances se han visto también enriquecidos con los aportes de Kenneth Andrien (1985), quien se enfoca en la crisis económica virreinal en la época de la Palata, planteando que, en la segunda mitad del siglo XVII, el sistema económico colapsa debido a la crisis de la minería potosina. A similares conclusiones llegan Peter Bakewell (1984), Enrique Tandeter (1982) y Herbert Klein (1994), el primero, a través del estudio de la contracción de los indios mingados en Potosí; el segundo, mediante el análisis del subsidio que las empresas mineras recibían del trabajo forzado de los indígenas; y, el último, con un examen de la fiscalidad real y los problemas relacionados con la recaudación de las Cajas reales. En esta vía de investigación, Ignacio Gonzáles Casasnovas (2000) se suma a ella investigando la cuestión de la mita de Potosí en las últimas décadas del siglo XVII y principios del XVIII. Asimismo, Carlos Lazo (1992, $1997,2001)$ se refiere al periodo de gobierno del virrey, encuadrado en el objetivo de poner en evidencia el desarrollo de dos cursos económicos paralelos y contradictorios en el Perú colonial.

Por ello, este artículo busca asociar a la Palata con esta línea de trabajo, resaltando la actuación del duque en el restablecimiento del eje económico medular de la economía colonial asentado en Lima y Potosí. Este núcleo vital estrecharía la dependencia entre el Perú y España a través de la implementación de políticas reformadoras dispuestas a maximizar los beneficios económicos de la corona hispana. Por este aspecto se considera a la Palata un virrey reordenador, pues logró elaborar una política dirigida a reinsertar al virreinato peruano en los roles que le fueron asignados. Nuestro estudio destaca esta actuación, pero a la vez deja ver los resultados de la implementación tardía de dichas reformas, que a la larga no lograron revertir el poder de las economías regionales.

Las fuentes utilizadas para esta investigación están conformadas por testimonios cualitativos y cuantitativos obtenidos de fuentes primarias de las series Superior Gobierno, Moreyra y 
Miscelánea, ubicados en el Archivo General de la Nación (AGN). Complementariamente, se ha examinado manuscritos inéditos, así como éditos coloniales y postcoloniales, que forman parte del fondo documental de la Biblioteca Nacional del Perú (BNP). La síntesis del estudio, que por sus características constituye una obra de historia económica colonial, contiene un informe narrativo y una descripción estadística compuesta por tres matrices y tres gráficos lineales.

\section{EI siglo XVII y el declive de la monarquía española}

En el transcurso del siglo XVII, toda Europa vivió un periodo de crisis secular a la que Eric Hobsbawm ha denominado una "paralización general del desarrollo económico" (Hobsbawm, 1988, p. 8). Sobre esta interpretación existe un amplio debate relacionado con las explicaciones de las distintas corrientes historiográficas del siglo XX. Pese a ello, es importante resaltar que los datos que se poseen indican que en el devenir de la crisis existe un conjunto de elementos que estaban interactuando entre sí. Al producirse su activación tuvo lugar un efecto dominó que puso en marcha todo este proceso que signa este periodo. Parece ser entonces que fenómenos externos, como el cambio climático o las guerras, solo influyeron pero no determinaron el origen de la crisis, la cual se tradujo en una serie de problemas económicos internos que afectaron de distinta manera la vida económica, social y política de la Europa del siglo XVII.

Estas contradicciones económicas se manifestaron en un estancamiento de la producción agrícola de alimentos, que curiosamente coincide con lo que Fernando Rosas denomina, una “pequeña edad de hielo" (Rosas, 1998, p. 87), cuyo arco temporal va de 1560 a 1660. Este fenómeno afectó a los cultivos, acelerando una elevación de los precios y una gran inflación. La regresión económica y el descenso demográfico fueron las dos características principales de esta crisis, después de un proceso de expansión durante los siglos XV y XVI. En el caso del decrecimiento demográfico, en palabras de Hobsbawm, se nota que la población europea sufre en el peor de los casos una declinación y, en el mejor, una nivelación entre fines del siglo XVI y el siglo XVIII (Hobsbawm, 1988). Este decrecimiento poblacional se debe a tres factores: las epidemias, que afectaron constantemente a todos los países europeos; las guerras, especialmente en Europa central; y las hambrunas, producidas por las malas cosechas periódicas y la destrucción de los cultivos en las guerras.

Esto generó una depresión comercial luego del auge provocado por la abundancia de metales preciosos provenientes de América, lo que elevó los precios debido a la demanda de productos. El efecto inmediato recae en las principales rutas de comercio internacional, menos las controladas por Inglaterra y las Provincias Unidas (Países Bajos), que además se vieron beneficiadas con la decadencia del imperio español (Rosas, 1998). En cuanto a la industria, el sistema gremial artesanal corrió la misma suerte, porque surgieron otras formas más baratas de producción. En Gran Bretaña, los Países Bajos y zonas de Francia y Alemania, la industria se trasladó al campo y se generalizó el trabajo a domicilio, con lo que la producción industrial alcanzó un nuevo desarrollo, llevada adelante por hombres con horizontes capitalistas y puesta en práctica mediante una clase obrera rural explotable (Hobsbawm, 1988). Esto hizo que las antiguas potencias comerciales (España, Portugal, Italia y la Hansa) colapsaran, perdiendo así su hegemonía en el comercio mundial de aquel entonces.

El impacto económico de la crisis fue bastante disparejo y unas zonas fueron más afectadas que otras. La peor parte se la llevó la mediterránea, que dejó de ser el centro de desarrollo económico, de manera que Italia y España ingresaron a un gran período de decadencia. Entretanto, Francia vivió una situación intermedia, ya que políticamente adquirió una gran influencia a nivel continental, mientras que económicamente quedó muy rezagada frente a Inglaterra, que 
comenzaría a afianzarse como potencia mundial (Hobsbawm, 1988). Como consecuencia de estos cambios, se produjo la definitiva variación del centro económico de Europa, que pasó del mar Mediterráneo al mar del Norte; el renovado poder del Estado al intervenir en la economía directamente para contrarrestar la crisis, reforzó el absolutismo, incrementó la inversión de los aristócratas en tierras y consolidó la economía mundo capitalista gracias al desarrollo de políticas liberales (Rosas, 1998).

En el caso particular de España, como nos lo recuerda Pierre Vilar, entre 1450 y 1650, se sabe que esta potencia fue la primera en crear un imperio mundial. Gracias a la explotación de las minas de América, España transformó las condiciones universales de la circulación monetaria y, por algún tiempo, parecía asegurada su hegemonía en Europa (Vilar, 1980). Sin embargo, al llegar el siglo XVII, ella y el resto de países europeos entraron en un periodo de dificultad, momento que algunos autores como Dobb y Hobsbawm interpretan como clave en la transición del feudalismo al capitalismo, puesto que los países que salen reforzados de ella, fundamentalmente Inglaterra, se encaminan al proceso que comienza con la revolución burguesa que en el siglo XVIII les llevará a la Revolución Industrial; mientras que otros países salen en peores condiciones, primordialmente España, al perder la posición de centralidad que hasta entonces habían tenido en la civilización occidental (Avilés, 1986).

La crisis golpeó duramente al imperio español, acelerando el declive de la monarquía castellana, lo que se hará notorio durante el reinado de Felipe III y sus sucesores, quienes no lograron evitar la caída. Las razones de la decadencia se debieron a la crisis general del siglo XVII, por la que pasó Europa (como factor externo), y a una serie de factores internos expresados en una zozobra económica, que ocasionó la ruina de la agricultura, la ganadería y la producción manufacturera. En este orden, la desventaja industrial de España, en el plano manufacturero, la convirtió en víctima de otras naciones mejor preparadas (Tord y Lazo, 1981). Esto hizo que la plata que provenía de las Indias se destine a comprar estos productos de otras potencias, como Inglaterra y los Países Bajos.

Otra de las razones de la crisis española, en el análisis de Vilar, era que España consumía demasiados recursos y gastaba excesivamente fuera de sus fronteras, en una política desmesurada para sostener su supremacía (Vilar, 1980). Precisamente, mantener el poderío político-militar implicó que España se viese enredada constantemente en conflictos bélicos con otras potencias, lo que supuso un gran gasto de los fondos de la hacienda real, con resultados no muy favorables para la política imperial. En razón de que los reyes españoles desde Carlos I se sumergieron en una espiral crediticia en la que se desvaneció toda la riqueza indiana, se produjeron numerosas quiebras de la Real Hacienda. Esta situación fue evidenciada durante el reinado de los tres últimos Austrias (Ferreiro, 5 de mayo de 2016). En este sentido, Felipe III, al asumir su mandato, encuentra un reino agotado por conflictos del siglo anterior, con bancarrotas de la hacienda pública en 1575 y 1597. De manera que este monarca tuvo que emprender una política basada en el establecimiento de treguas y tratados de paz con sus enemigos.

Durante el reinado de Felipe IV, España nuevamente se ve envuelta en nuevas guerras, con derrotas que implican la pérdida de su otrora hegemonía. Como consecuencia, a pesar de quedar exhausta, la monarquía continuó sus esfuerzos para reconquistar Portugal y defender las posesiones que tenía en el norte de Europa, amenazadas por Francia (Burkholder y Chandler, 1984). En el mismo sentido, Carmen Fernández (2013) indica que, desde la segunda mitad del siglo XVII, en numerosas ocasiones la monarquía castellana tuvo que claudicar y postrarse ante Inglaterra en el continente americano, para obtener de ella la neutralidad en los encuentros hispano-franceses. Aunque, a veces, como indica la autora, esta política se convirtió, en la 
práctica, en una carta blanca, pues los ingleses actuaron a su antojo tanto en uno como en otro continente.

En esta etapa, España participó en la guerra de los Treinta Años (1618-1648), apoyando a los Habsburgo de Viena y a los príncipes católicos alemanes. Sin embargo, con la incorporación de Francia, el sino de la guerra cambió. Además, al tiempo que las tropas españolas eran derrotadas, ingleses y franceses atacaban los territorios americanos y apoyaban las rebeliones de Cataluña y Portugal. Finalmente, cuando concluyó el reinado de Felipe IV, éste se vio obligado a firmar la Paz de Westfalia (1648) y de los Pirineos (1659). En esos acuerdos, además de perder la hegemonía europea, España cedió a Luis XIII de Francia los territorios de Artois, Rosellón y Cerdaña, y en ese contexto se reconoció la independencia de las Provincias Unidas y de Portugal (Contreras y Zuloaga, 2014).

El último de los Austrias, Carlos II, halla una España seriamente disminuida por las conflagraciones anteriores, y trata de hacer lo posible para frenar el expansionismo de la Francia de Luis XIV. Empero, las continuas guerras con ésta mermaron los dominios hispánicos en Europa y América (Alonso y Martínez, 2000). Por último, la muerte del monarca sin dejar descendencia llevó a un nuevo conflicto, la guerra de sucesión española (1701-1713). Las continuas derrotas que sufrió el imperio, a pesar de que aún poseía vastos territorios coloniales, revelaron su debilidad en el afán de mantener su poderío en Europa. Las guerras por el predominio en el continente simbolizaron el fin de la influencia hispana en el Viejo Mundo y del ascenso de Francia como potencia hegemónica.

A todo lo anterior se añade que, entre las luchas y el declive de la producción, la población española sufrió una drástica reducción demográfica, cuyas principales causas fueron: la mortalidad causada por las guerras, las pestes y el hambre, así como la emigración a América y la expulsión de los moriscos (1609). Esto último, que se sumaba al lanzamiento de los judíos en el siglo XVI, contribuyó a privar a España de una base social que le hubiera permitido conseguir el tan deseado desarrollo económico. En este punto, la sociedad estamental española vivió un proceso de polarización marcada por el empobrecimiento de un campesinado que constituía la mayor parte de la población, la debilidad de la burguesía y las clases medias, y el crecimiento numérico de los grupos sociales improductivos como la nobleza y el clero en un extremo, y los marginados (pícaros, vagos y mendigos) en el otro.

La conducción política imperial también tuvo mucho que ver con los graves problemas que llevaron a la decadencia del imperio, dilema que empieza a exteriorizarse con fuerza a partir de 1665, con un claro debilitamiento de la monarquía (Lynch, 1991). En este sentido, el derrumbe de la autoridad real, fue el punto de quiebre del poderío político-económico de España. Desde esta perspectiva, los Austrias fueron incapaces de superar dos grandes obstáculos: la autonomía de las regiones (rebeliones de Portugal y Cataluña) y el poder político de la aristocracia (Lynch, 1991). El encumbramiento político de la alta nobleza puso en evidencia la pérdida de control por parte de la corona (Burkholder y Chandler, 1984). Este hecho se manifestó en la sucesión de favoritos (validos), quienes ejercieron el poder durante el reinado de los últimos monarcas de la dinastía austriaca. Esta bancarrota política fue aprovechada por estos nobles, quienes la utilizaron para beneficiarse a expensas del Estado. Por lo dicho, estos personajes poco o nada hicieron para evitar la corrupción general y la declinación que sufrió el reino. Por lo tanto, los limitados esfuerzos hechos para revitalizar la autoridad real siempre estuvieron condenados al fracaso (Burkholder y Chandler, 1984). 
La confluencia de todas estas circunstancias repercutieron seriamente en el comercio metropolitano, ocasionando una depresión comercial que afectó a sus principales rutas comerciales, tanto en el Mediterráneo como las que mantenía con sus colonias americanas. De manera que la pérdida del monopolio en el comercio mundial de la época habría de favorecer a sus más cercanos competidores. Perder el centro de gravedad del comercio permitió que los Países Bajos e Inglaterra, al quitarle el control al imperio español, se convirtieran en las nuevas potencias comerciales (Braudel, 1984).

Ante esta grave crisis económica, la monarquía castellana se vio urgida de contar con las remesas monetarias de plata provenientes de sus dominios americanos, con los que esperaba solucionar sus principales problemas económicos. Sin embargo, hubo una merma de la plata llegada de América, por un lado, a consecuencia del contrabando en el nuevo continente y, del otro, por la disminución de su producción en las primeras décadas del siglo. Ambos factores le ocasionaron al Estado español graves dificultades económicas.

En suma, desde la última década del siglo XVI, España estaba en bancarrota fiscal, a pesar de los ingentes ingresos de las minas de Potosí y Zacatecas, y a pesar del cobro de los impuestos al comercio ultramarino. Esta crisis se produce precisamente por gastos no productivos en que incurre la monarquía, lo cual admitía un alto costo que obligaba a la corona a recurrir a créditos. No obstante, un tema significativo es que España no llega a cambiar su estructura económica y dar el salto hacia la manufactura en el siglo XVII. Por lo tanto, el imperio colonial termina sin un centro propio de abastecimiento de productos manufactureros, tal y como lo exigía la variante del mercantilismo que predominaba en Francia e Inglaterra.

Esta endémica crisis fiscal obliga a la metrópoli a buscar recursos. Como se ha dicho, la producción manufacturera es la solución a largo plazo, pues es una producción con alto valor agregado. Empero, España desarrolla poco sus centros productores (incluso, el siglo XVII es menos desarrollado que el siglo XVI en manufacturas, sobre todo en Cataluña y algunos puntos de Castilla). Pero a pesar de lo señalado líneas arriba, el tema es que España recurre a mercaderías extranjeras para completar los montos que envía a sus colonias, pues su propia producción fabril no es suficiente ni segura. Así, pierde la oportunidad de desarrollar ella misma una industria manufacturera sólida y extendida.

Cuando la España de los Austrias busca revertir esta situación, se encuentra con que es muy difícil. El resultado de todo esto es que la corona castellana no recibe los recursos que bien podrían haberle dado su condición de dueña de las colonias más ricas: México y el Perú. Sobre todo, le preocupa el Perú, porque la corrupción y el contrabando en el virreinato es tal que los burócratas peruanos no recaudaban todo lo que debían (descaminos) y, de lo recaudado, solo enviaban a la metrópoli una parte muy pequeña y hasta ridícula, cuando más el $20 \%$ al año. El resto se lo reparten entre los poderosos del país vía los gastos de defensa y otros. Estas contingencias le plantearon a la monarquía encontrar una salida rápida, segura y fácil para hacerle frente a esta dificultad. La alternativa fue la de obtener fondos aumentando los tributos. Sin embargo, cuando se intentó hacerlo, la corona recibió un rotundo rechazo que desembocó en una férrea oposición de los grupos locales de poder en el Perú, quienes habían generado redes e intereses económicos que eran diametralmente contrarios a los de la metrópoli imperial.

\section{Desestabilización del orden económico oficial en el Perú colonial}

Desde la segunda mitad del siglo XVI, la economía colonial con la metrópoli hispana se sustentaba, de acuerdo con las ideas mercantilistas, en el intercambio comercial y la extracción de metales preciosos. Todos los bienes, en especial los importados, se obtenían mediante el intercambio 
de monedas hechas de plata (pesos) y en menor proporción de oro (doblones). En virtud de esta orientación, el comercio exterior estaba sujeto a dos principios: el exclusivismo y el monopolio comercial. Como lo ha resumido Kenneth Andrien (1985), durante el apogeo de la producción de la plata, Lima y el puerto del Callao se convirtieron en el centro comercial del virreinato. Desde este foco, toda la mercancía importada de Europa se canalizó a través del Callao, donde el tráfico podía ser más fácilmente supervisado y gravado. A partir de ahí los demás centros mineros, agrícolas, manufactureros y centros administrativos virreinales pasaron a depender de los comerciantes de Lima para vender sus productos y suministrarles mercancía de Europa, Asia y las Américas. La dinámica de este comercio se desarrolló a través del intercambio de la plata de las minas del Perú y el Alto Perú por estos bienes importados. Este proceso resultó muy rentable para los mercaderes limeños, quienes, mediante el control de la oferta de las importaciones altamente deseables, mantuvieron siempre altos los precios (Andrien, 1985).

A consecuencia de lo anterior, para la segunda mitad del siglo XVII, este proyecto económico establecido desde la época del virrey Toledo colapsó. Al respecto, Andrien (1985) delinea el colapso de este circuito comercial en los siguientes términos: primero, por la contracción de la minería potosina, expresada en una reducción de los quintos reales; y segundo, por la retracción de la actividad comercial, que tenía como centro de operaciones a la ciudad de Lima. Complementariamente, también se observa una pérdida del poder político de Lima frente a los gobiernos municipales de provincias. Este resquebrajamiento estuvo ligado al debilitamiento de los Habsburgo, quienes relajaron el control metropolitano sobre los territorios americanos, lo que acentuó la pérdida del dominio político sobre el virreinato del Perú (Amadori, 2012; Burkholder y Chandler, 1984).

En estas condiciones, el colapso del eje económico Lima-Potosí provocó una severa tensión en la economía peruana, pues la decadencia progresiva de la minería potosina dará lugar a una enorme reducción del mercado interno desarrollado alrededor de este centro minero (Klein, 1994). El estudio de Andrien destaca que la alta productividad de la industria de la plata en los siglos XVI y principios del XVII dio paso a un periodo de declive gradual en 1650. Algunas de las razones de esta disminución se atribuyeron a inevitables dificultades técnicas de la industria (inundaciones de los socavones, aumento del costo del mercurio y disminución de la calidad del mineral). Asimismo, el tráfico ilícito de mercurio (azogue), insumo extraído de las minas de Huancavelica que por problemas tecnológicos comenzó a escasear, intensificó el flujo de contrabando de la plata, lo que contribuye a la disminución de los impuestos a la industria minera (Andrien, 1985).

La onda de choque de esta crisis, como documenta Carlos Lazo, repercutió en la desarticulación del régimen de flotas. Y de igual manera, en el desenvolvimiento de una grave crisis económica que se manifestó en un descenso de la producción minera (evidenciada en una disminución del quinto, que era el índice para medir la producción), lo que originó la contracción de los ingresos fiscales. Igualmente, la reducción de la recaudación fiscal ocasionó que los gastos totales del fisco se contrajeran de 100 a 21. Del mismo modo, la amonedación en Lima y Potosí bajó de 100 a 6 y de 100 a 49, respectivamente. Esto significa que la plata salía volando para pagar los productos del contrabando. En último lugar, se contrajo la producción artesanal con una caída porcentual que osciló entre 40 y 76\%, lo cual se traduce en una reducción de 100 a 25 , índice determinado mediante el estudio de las alcabalas encabezonadas (lo que cada gremio pagaba por alcabalas) (Lazo, 1992).

Como resultado de este hecho, el dominio comercial de la comunidad de Lima finalmente declinó, junto con la industria minera. Por esta razón, las investigaciones de Andrien señalan 
que las ganancias llegaron a ser más difíciles de mantener en vista que la productividad de las minas de plata disminuyó. Otro factor que redujo las ganancias del comercio en el Atlántico fue el declive de la industria castellana. Los bienes vendidos en las ferias de Portobelo a menudo se obtenían originalmente de productores en Francia, Inglaterra y Países Bajos. Dado que los intermediarios en Sevilla marcan el precio de estos bienes extranjeros para hacer un beneficio en la transacción, el precio total de las importaciones europeas aumentó aún más, reduciendo el margen de ganancia de los comerciantes de Lima. A fin de superar estos inconvenientes, los limeños comenzaron a tratar de restringir el suministro de los productos europeos, con el propósito de mantener los precios altos y sus beneficios a un nivel aceptable. Como consecuencia, el número de salidas del Callao a Panamá disminuyó de 29 en la primera mitad del siglo a solo 19 entre 1650 y 1700 . A causa de ello, la disminución de la base económica y comercial del virreinato del Perú durante las tres primeras décadas del XVII proporcionó un poderoso impulso para la diversificación económica. De manera que los comerciantes, mineros y otros magnates se vieron en la necesidad de invertir en otros negocios más lucrativos (Andrien, 1985).

En este curso queda claro, siguiendo la tesis de Andrien, que el siglo XVII fue un período de transición y reajuste de la economía virreinal. Esta economía de consumo estuvo muy ligada al mercado productor europeo, sustentada en los ricos yacimientos de plata del Alto Perú. Sin embargo, como se ha dicho, conforme fue disminuyendo la productividad de las vetas de plata y los lazos comerciales con España se debilitaron, la inversión de capital se desplazó hacia otras empresas más productivas (Andrien, 1985). De esta manera, al verse afectada la totalidad de la producción peruana por efecto de la crisis de la minería iniciada hacia 1620, los propietarios se adaptaron y generaron una economía productiva y comercial no tan dependiente de la minería potosina. Esta economía pasó a tener ritmos y una dinámica propia, lejos de las alteraciones de los vaivenes de Potosí. Es decir, la economía se adaptó a un mercado interno muy sólido que se sustenta en lo que el virrey Toledo y el régimen colonial les diera y asegurara: trabajadores como yanaconas; propiedad legal sobre los medios de producción; y un sistema de "venta" compulsiva (reparto de mercaderías) de los corregidores y comerciantes (que "venden" productos mayormente peruanos en un mercado cautivo).

Esto quiere decir que, frente a la caída del eje oficial del Perú colonial, van a surgir otros circuitos económicos organizados alrededor de nuevos centros mineros productores de plata en Castrovirreyna y Oruro. Estos se convertirán en importantes polos de desarrollo para un vasto y diversificado mercado interno (Lazo, 2001). Consiguientemente, en el Perú se produce una situación de fortalecimiento de los sectores propietarios (mineros, manufactureros, agropecuarios, comerciantes, etc.), que aprovechan la debilidad española y las necesidades financieras de la metrópoli. Consiguen la propiedad de tierras, pastos, obrajes, etc., usan el monopolio comercial, adquieren puestos en la burocracia colonial, y de esta manera se hacen fuertes en los aspectos económicos, políticos y sociales. Con ello, logran manejar el país a su manera, y lo hacen redefiniendo el mapa económico, pero sin que esto se oponga a sus actividades.

En esta línea, de un modo explícito, la minería siguió dominando la economía colonial, pero ligada a la reactivación de la economía local, constituida por centros regionales hacia donde fluye el capital. Estas economías provinciales adquirieron un dinamismo propio y una autonomía en la producción de una vasta variedad de productos agrícolas y manufacturados, en zonas como Saña, Cuzco, Cochabamba y regiones periféricas como Chile y Quito. Esto permitió el florecimiento de economías que se especializaron en actividades destinadas al consumo local o al intercambio intercolonial. En este sentido, conforme la economía del virreinato se fue haciendo más diversificada, más autónomo era el consumo de sus habitantes. De esta manera, el Perú dejó 
de necesitar de afuera vino, azúcar, harina, tejido de lana y algodón, vidrios, cuero, pólvora y la mayoría de artesanías (Contreras y Zuloaga, 2014). Al mismo tiempo, se estimuló la industria textil a partir de los obrajes y, de igual manera, se hizo lo propio con el intercambio comercial de bienes, tanto legales como de contrabando, a lo largo de la costa del Pacífico sur, América Central, México y el Lejano Oriente (Andrien, 1985). Este comercio creció significativamente y favorecido por la mejora de las vías de comunicación y el despegue de la industria naviera en los astilleros de Guayaquil.

El crecimiento de estos centros urbanos impulsa la demanda de los bienes producidos localmente. Además, las organizaciones clericales jugaron un papel importante a través de la inversión en tierras y la extensión del crédito a los productores locales y al gobierno. Por su parte, el gobierno virreinal también proporcionó un acicate a la reestructuración de la economía por retenciones de impuestos, que normalmente se enviaban a España para que se gastasen dentro del territorio (Andrien, 1985). Al hacerse autosuficiente el virreinato peruano, se produce un repliegue del comercio con la metrópoli, lo que hizo que la corona no pudiese abastecer a América de las mercaderías demandadas por la élite. Al mismo tiempo, sin quererlo, promovió el fortalecimiento de los grupos criollos locales en las colonias, al no ser capaz de enviar suficientes burócratas para ocuparse de la administración colonial (Contreras, 2002).

En cuanto a lo primero, la política comercial española fracasó, puesto que, al ser la producción manufacturera tan pequeña, la metrópoli se vio forzada a adquirir en el resto de Europa los productos que necesitaban sus colonias. Por eso los criollos comenzaron a satisfacer la demanda interna con la producción local de bienes, cuya importación resultaba demasiado costosa (Contreras, 2002). De esta manera, fue la misma metrópoli la que indirectamente alimentó la autonomía de los colonos indianos (Burkholder y Chandler, 1984). En relación a lo segundo, el sistema de control político que España tenía en sus territorios ultramarinos, cuyo objetivo era limitar las autonomías locales, fue seriamente afectado con el acceso de los criollos a los puestos de oidores y corregidores mediante la venta de cargos públicos. De hecho, la misma corona, por sus propias necesidades económicas, permitió que criollos pertenecientes a prominentes familias locales accedieran a estos cargos, quienes, una vez posesionados de los mismos, actuaron en beneficio de sus propias ganancias económicas (Contreras, 2002). Con ello, quedó de lado el celo por la defensa de los intereses regios.

A la larga, esta relajación ocasionada por la venta de cargos fue una bomba de tiempo que estalló en la cara de la misma corona, pues, cuando ésta detona, privó a Madrid de los recursos económicos que necesitaba (Burkholder y Chandler, 1984). Se inició así una tensa relación entre el Estado metropolitano y el virreinato peruano (Contreras, 2002). El punto focal de este enfrentamiento fue que Madrid comenzó a exigir mayores contribuciones al gobierno de Lima. Mientras tanto, las élites en el virreinato se oponían firmemente a estas exacciones fiscales, por considerar que tales impuestos ponían en peligro sus inversiones de capital. Esta tirantez se convirtió así en una constante que signa la relación entre la metrópoli y el virreinato del Perú durante la segunda mitad de este siglo (Andrien, 1985).

La irresolución de este problema determinó que la corona se decida por la adopción de medidas que restituyeran su soberanía en estos territorios, reordenando y manteniendo el control colonial del Perú como fuente aprovisionadora del numerario. En este contexto se acuerda enviar a tierras peruanas a un funcionario real (duque de la Palata) con la misión de sacar del Perú el mayor provecho para España. Pero, al tratar de hacerlo, entra en conflicto con los intereses de los empresarios peruanos (obrajeros, hacendados, mineros, comerciantes, etc.), quienes no estaban dispuestos a ver mermadas sus operaciones económicas. Llegados a este punto, el asunto es que 
con la intervención imperial de la Palata, que buscaba neutralizar la acción de los propietarios provincianos para favorecer la economía de exportación de los propietarios imperiales, la metrópoli no presenta una alternativa radicalmente diferente (en base a una economía manufacturera) y por eso fracasa. Por esto es que el virrey duque de la Palata, durante su mandato de gobierno, no consiguió más que realizar cambios pequeños y medianos para reorganizar la producción, teniendo como eje la minería potosina y encontrando en el proceso serios tropiezos que hicieron trastabillar todas sus reformas.

\section{El colapso del eje Lima-Potosí y las medidas reordenadoras para restablecerlo}

Durante el siglo XVII, el desplome del foco económico ubicado en Lima y Potosí puso en evidencia su insostenibilidad, puesto que su desarrollo, el cual estaba adaptado a un mercantilismo colonial, orientó su crecimiento económico hacia fuera, lo que originó deterioros en sus líneas matrices (minería y comercio), planteando así la necesidad de reajustarlo. En este contexto se produce la intervención del duque de la Palata, quien buscó revertir el daño colateral provocado por las consecuencias negativas de la política metropolitana en la región. Para lograrlo, impulsó todo un programa de reformas, expresado en una serie de medidas conducentes a: el establecimiento de empresas productivas; el saneamiento monetario y fiscal; el combate a los circuitos regionales que competían con Lima; la protección del indio en cuanto a los abusos; y la fijación de un tope salarial.

Este conjunto de disposiciones, previa a su llegada a Lima, fueron tratadas en varias reuniones con los miembros del Consejo de Indias a lo largo de 1680. En ellas, la Palata y los consejeros concretaron las medidas que debía adoptar en el Perú (Gonzáles, 2000). En este orden, el virrey pone en ejecución el desarrollo de un programa macroeconómico orientado a preservar el equilibrio, conteniendo y suprimiendo los cambios que amenazaban rebasar la estabilidad del orden colonial. Asimismo, ello tendió a encauzar, sin menoscabos, la dirección de los beneficios económicos hacia la metrópoli y, desde luego, a los empresarios indianos (criollos limeños).

Sin embargo, los esfuerzos de la Palata para aumentar la base imponible del virreinato se vieron frustrados en 1687 debido a los grandes terremotos que devastaron Lima y toda la costa central. Esta destrucción obstaculizó el comercio y provocó serios daños en las tierras agrícolas costeñas, que se vieron severamente afectadas en su productividad por la destrucción de su sistema de riego y la erosión del suelo. Por esta razón, el virrey pasó la mayor parte de sus restantes dos años de gobierno tratando de reconstruir Lima y el Callao, e intentando recuperarse de las consecuencias económicas del terremoto. Por ello, las cuestiones de la reforma financiera y administrativa, por él impulsada, dejaron de ocupar una posición preeminente dentro de su preocupación (Andrien, 1985).

Al margen de esta contingencia, la historia de este colapso y las providencias tomadas para contrarrestarlo, serán vistas en las líneas que siguen, teniendo como hilo conductor la intercepción de dos hechos generales. Uno estructural, correspondiente a una redefinición del mapa económico del Bajo Perú, que dejo de lado la ya avejentada vertebra de la economía virreinal: el eje LimaPotosí. Y otro coyuntural, de tráfico ilícito comercial y de metálico precioso, así como una corrupción generalizada en todos los ámbitos gubernamentales en proporciones inusitadas.

\subsection{Colapso del circuito comercial Lima-Potosí}

En el Perú colonial, de acuerdo con los aportes de la historia económica de este periodo, la corona española organizó la vida económica y social del virreinato sobre los sectores que más tasas de beneficios brindaban, como la minería y el comercio trasatlántico. Al articularse un eje sobre la base de estas dos actividades, la economía minera logró montar una red de polos 
productivo-comerciales alrededor de los principales campamentos (abastecimiento de productos agrícolas, bienes textiles, mobiliario doméstico y otros tipos de mercancía) (Contreras, 2002). De esta manera, el manejo exclusivo del comercio le dio a Lima el control sobre la región de Potosí y su decisiva producción de plata (Sempat, 1982). Con ello, estas dos ciudades irradiaron impulsos claves para la dinámica de acoplamiento económico del espacio colonial peruano. Por su capacidad de mercados masivos de consumo, estas ciudades transmitieron y extendieron sus efectos a otras regiones (Sempat, 1982).

Hacia fines del siglo XVII, Madrid estaba empezando ya a no lograr sus objetivos esenciales, como conseguir que América siguiera siendo un mercado colonial cerrado, y garantizar que las remisiones de numerario con las que se pagaban las mercaderías importadas fueran enviadas a España (Fisher, 1992). Este régimen monopólico de los mercaderes sevillanos se desestabilizó debido a la avalancha de mercaderes europeos que deseaban participar de las riquezas del Nuevo Mundo, lo que originó un cambio en los circuitos y agentes comerciales, que devino en una crisis del circuito oficial (Lima-Potosí-Sevilla) en la segunda mitad de este siglo (Suárez, 1995). En perspectiva, este desequilibrio habría de minar la relación política entre Perú y España (Andrien, 1985).

La otra variable fue una coyuntura de tráfico ilegal de mercancías, contrabando de plata y una corrupción extendida en el aparato de gobierno virreinal. En virtud de esta orientación, la crisis económica, más que afectar la producción misma, redireccionó la distribución de la riqueza argentífera, encaminándola hacia circuitos de comercialización no oficiales, en los que se eludía el pago de los correspondientes derechos fiscales (Lazo, 1997). Esto dio lugar a que, en el transcurso del siglo XVII, la ordenación y el curso del orden económico oficial (especialmente a fines de esta centuria) sufriese la acción desestabilizadora de los empresarios provincianos. Esta actuación se manifestó en los siguientes órdenes: en el campo laboral (desarticulando el régimen mitayo potosino), en el orden productivo (creando circuitos económicos regionales paralelos al oficial) y en el orden político (creando el concepto de patria aristocrática anticolonial) (Lazo, 2001). Estos aspectos serán ampliados a continuación en forma detallada.

\section{- Desarticulación de la mita minera potosina}

Para satisfacer la demanda de mano de obra requerida por los empresarios mineros, el virrey Toledo dio en Huamanga, el 20 de enero de 1571, 75 ordenanzas que destinaron el número de mingados obligados a trabajar en la mita minera de Potosí (BNP, Ms., F-269). Por medio de ellas, asigna 16 provincias circunvecinas a ese centro minero (Konetzke, 1972), al disponer: "que los indios no vengan de más distancia de 20 leguas" (BNP, Ms., F-269). En una palabra, las comunidades de dichas provincias, fueron adscritas al servicio de mita minera potosina, tal como ilustra un testigo de la época, quien a propósito anotaba:

Moran alrededor de la villa [de Potosí] ... más de cuarenta mil indios ... dedicados para entrar a trabajar en las minas, y acuden todos los meses de sus ayllos que son provincias, los envían los corregidores y los llevan alcaldes de indios, y acuden a sus mitas conforme sus repartimientos. (León Portocarrero, 1958, p. 99)

Esta asignación fue ejecutada con la información de los censos de indios recogidos en las visitas, por lo que se fijó aproximadamente en 95000 el número de mingados para Potosí (Bakewell, 1984). De esa cifra, la séptima parte (entre 13300 y 13 500) debía acudir cada año a trabajar en la mita, requiriéndose, para las labores de las minas, la movilización diaria de 4500 mitayos distribuidos en tres turnos (Konetzke, 1972), que semanalmente rotaban; de modo que 
un indígena servía una semana y "descansaba" dos como alquila. Como el tiempo de trabajo obligatorio debía durar cuatro meses (16 semanas), cada servidor estaba compelido a permanecer 48 semanas en la villa (Tord y Lazo, 1984).

Durante el siglo XVII se nota una contracción del volumen de la mita, en el que el número de naturales destinados a Potosí se redujo de 95000 a menos de 20000 (Andrien, 1985). Los cálculos manifiestan que esta reducción fue paulatina, ya que el número de indios de las 16 provincias mitayas decreció vertiginosamente de 40115 aborígenes en 1633, a 16000 en 1662 , y finalmente a 10633 en 1683 (Konetzke, 1972), tendencia que se destaca en las cifras que se presentan en la tabla 1 y la figura 1 .

Tabla 1. Disminución de mitayos asignados a la mita minera de Potosí (siglo XVII)

\begin{tabular}{|c|c|c|c|}
\hline Año & Total de mitayos & I.E. & Séptima de mita \\
\hline 1571 & 95000 & 100.0 & 13571 \\
\hline 1600 & 32788 & 34.51 & 4684 \\
\hline 1611 & 30891 & 32.51 & 4413 \\
\hline 1634 & 28805 & 30.32 & 4115 \\
\hline 1651 & 29400 & 30.94 & 4200 \\
\hline 1670 & 12712 & 13.38 & 1816 \\
\hline 1676 & 11718 & 12.33 & 1674 \\
\hline 1683 & 10423 & 10.97 & 1489 \\
\hline
\end{tabular}

Base: $1571=100.0$

Fuente: Olivera (1905)

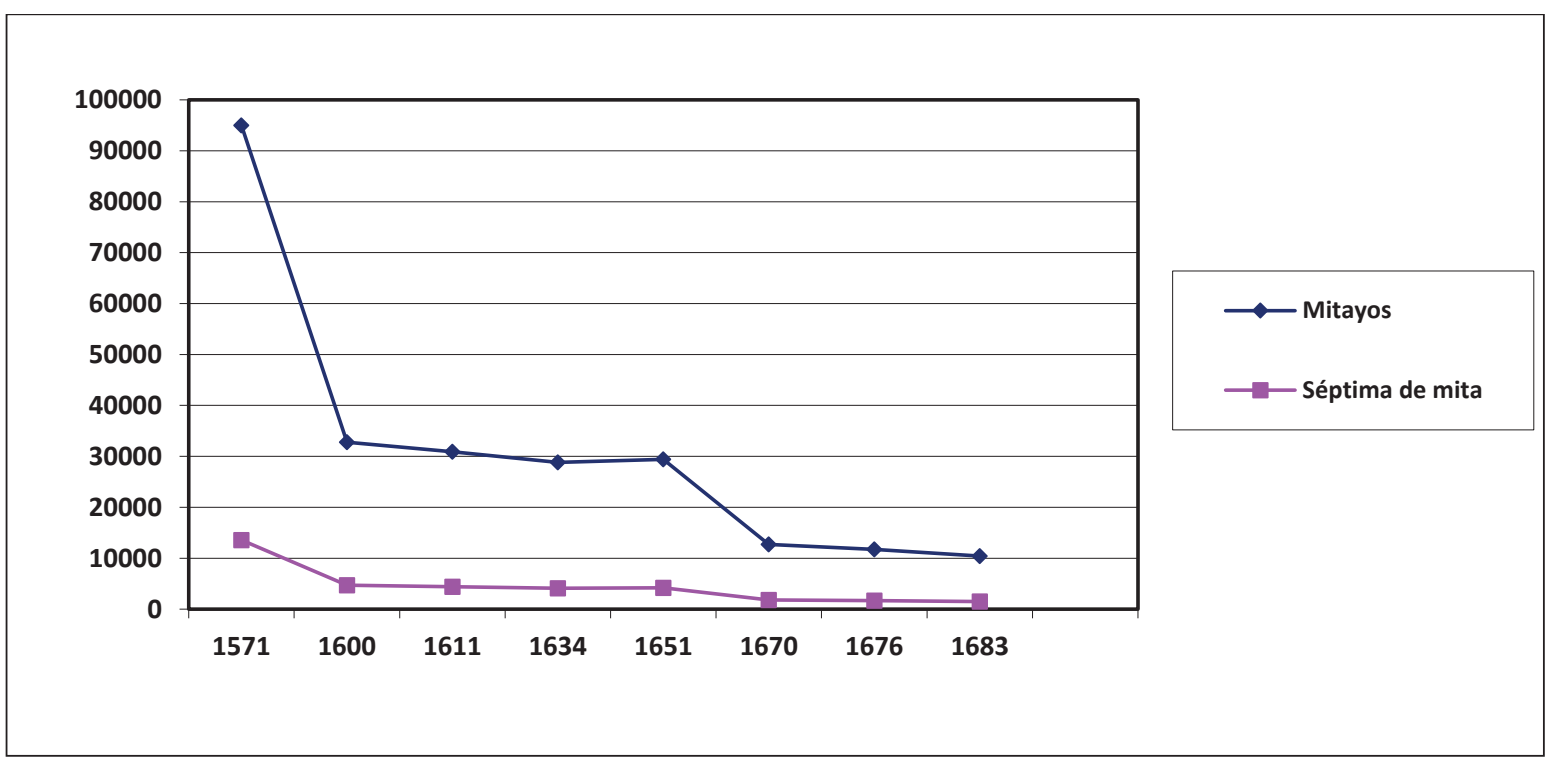

Figura 1. Progresión del decrecimiento de la mita minera de Potosí.

Fuente: Elaboración propia del autor.

Esta disminución de la gruesa de indios, y por ende del trabajo indígena, se subsanó en parte con los indios de alquila, llamados también indios de faltriquera (Andrien, 1985). Esta es la razón, según se desprende de un testimonio de este tiempo, por la que cuando "se empezó a sentir la falta de Indios de mita ... sobraban Indios voluntarios, que por su jornal ... acudían tantos, que aunque faltassen muchos de la mita asignada, no se echaba de menos en el fruto de la cosecha" (La Palata, 1859, pp. 223-224). 
Sin embargo, este sistema de trabajo se vio afectado por la escasez de plata y la poca ley del metal, que hacían sumamente onerosos los costes de los empresarios mineros, por lo que éstos:

no pudiendo ya ... costear, por la pobreza de los metales, el gran gasto de los jornales de los indios alquilados, que llaman de minga, empezaron a sentir la falta de los indios de mita, que ... les dexó asignados el señor Virrey Don Francisco de Toledo. (La Palata, 1859, p. 224)

Lógicamente, este desmoronamiento del régimen mitayo se debe a la forma de trabajo en las minas. Este régimen, como indica un especialista, sometía al indio a trabajos forzados, a maltratos, a una precaria seguridad dentro de la mina, a penurias y privaciones durante el viaje a Potosí, etc. (Konetzke, 1972). Lo que a la larga provocó que la población nativa decreciese notablemente, en virtud de estos estragos producidos en sus mismas condiciones de vida. No obstante, para los grupos dominantes, que tenían trazado un perfil social negativo del indio, defendían este sistema de explotación afirmando que el trabajo de las minas no acababa a los indígenas, sino, al contrario, los preservaba de los daños espirituales y corporales que se derivan de su ociosidad (Olivera, 1905). Es más, estaban convencidos de que "para la salvación de los Indios, y su cobranza y gobierno ... es menester obligarlos al trabajo por fuerza" (La Palata, 1859, p. 244).

Por este motivo, muchos naturales de provincias mitayas huían a otras comarcas y a las ciudades u optaban por entrar como yanaconas al servicio de terratenientes españoles (Konetzke, 1972), acción en la que también tuvieron mucho que ver los empresarios criollos provincianos, quienes contribuyeron con la desestabilización de este orden laboral al impulsar la yanaconización de los indios (Lazo, 2001). Esta situación, en el primer caso, dio lugar al fenómeno del forasterismo; y en el segundo, a la adscripción de los naturales a determinadas unidades económicas agrícolas mediante el yanaconaje. Esta circunstancia ha quedado testimoniada y se pone de relieve en algunos documentos, como el informe del obispo limeño Pedro Villagómez, fechado el 26 de julio de 1663 (Glave, 1985), que, al referirse a la disminución del número de indios en las mitas, señala entre sus causas: el aumento de la malicia en los naturales; el interés de los hacendados en la fuerza de trabajo (yanaconas); y los aprietos que recibían los indios en sus pueblos (Glave, 1985).

Esta realidad ponía en serios predicamentos a los curacas, debido a que no les era posible atender el envío de indios para las mitas, como lo testimonia el curaca de Ubinas, Diego Coahuila, en una consulta hecha el 25 de noviembre de 1683, en donde deja constancia que su incumplimiento con la cuota de indios mitayos se debía a que parte de los naturales de su pueblo habían fallecido producto de enfermedades, "y algunos se le an ausentado, y no se save donde, y otros pocos se an ausentado con sus mugeres y familias en la ciudad de Arequipa, y en los pueblos de Omate y Puquina" (BNP, Ms., B-1683, 1684, Doc. 1, fol. 1). El capellán Diego de Cáceres y Ulloa observaba en la misma consulta que por este proceder "finxen los indios, como hijos de la mentira, muchas falsedades maiormente influidos y fomentados de poderoso favor, por ver si con esso pueden evadirse de las mitas y de otros travaxos personales en que les pone el Rey" (BNP, Ms., B-1683, 1684, Doc. 1 fol. 4v).

A similares conclusiones arribó, décadas más tarde, el virrey duque de la Palata, al comprobar que la merma de mitayos no dependía de la despoblación de las doctrinas, sino de que los indios, por escapar de la mita, se refugiaban en otras provincias, en las ciudades o en las haciendas, donde les era fácil ocultarse protegidos por curacas, estancieros, obrajeros, curas y corregidores, interesados en aprovecharse de sus servicios (Lorente, 1870). Por esta razón, este comisionado real, en un despacho remitido al rey, se quejaba que desde Paita hasta Potosí se hallan los poblados faltos de gente, atribuyendo esta baja poblacional a tres motivos: el trabajo en 
las minas; la fuga de las poblaciones a ciudades y provincias que no mitaban; y la retención de indios, que los españoles realizaban para que éstos laboren en sus haciendas, trapiches de azúcar, estancias y obrajes (La Palata, 1859). En este contexto, el descenso de la población nativa y, por ello, el trabajo indígena en las minas es un factor que contribuyó a la crisis de Potosí.

\section{- Decaimiento de la producción minera}

Otro componente que intervino en la coyuntura de la crisis fue la caída de la producción minera, lo que en el virreinato peruano significó la decadencia de Huancavelica y Potosí (Flores Galindo, 1977). Este colapso, en lo que a Potosí se refiere, se evidencia con mayor profundidad desde la segunda década del XVII, en parte a causa del desplome demográfico de la fuerza de trabajo india (epidemias y sobreexplotación), y en parte por el agotamiento del filón que hizo descender la producción de plata (Anderson, 1979). A tal punto llegó la declinación de la minería argentífera altoperuana que algunos autores no han dudado en conceptuarla de dramática (Klein, 1994). De un modo explícito, el virrey duque de la Palata, en sus memorias de gobierno, reconocía la verosimilitud de esta situación al afirmar que:

la causa [del] ... descaecimiento [de Potosí] es natural, porque ... ha más de cien años que se esta sacando [mineral] ... con que naturalmente se ha ido disminuyendo y acabando aquella riqueza, y nadie podrá discurrir quanto tardará en criarse otra igual. (La Palata, 1859, p. 22)

Evidentemente, esta merma de la producción argéntea repercutió sobre los montos de amonedación de plata y la recaudación de derechos fiscales, en la medida que la extracción de este metal precioso ya no fue capaz de proporcionarle a la real hacienda los esperados ingresos provenientes del cobro del quinto y de los derechos de señoreaje y braceaje (Lorente, 1870). Esta contracción, en ambos casos, es reconocida de 1655 en adelante. Esta realidad imperante se refleja en las cifras, que nos han permitido reconstruir las series de rendiciones trianuales y quinquenales con los detalles de cotidianeidad cuantitativa, referida en las tablas 2 y 3 y figuras 2 y 3 , las cuales nos ofrecen los correspondientes indicios testimoniales que explican las tendencias señaladas.

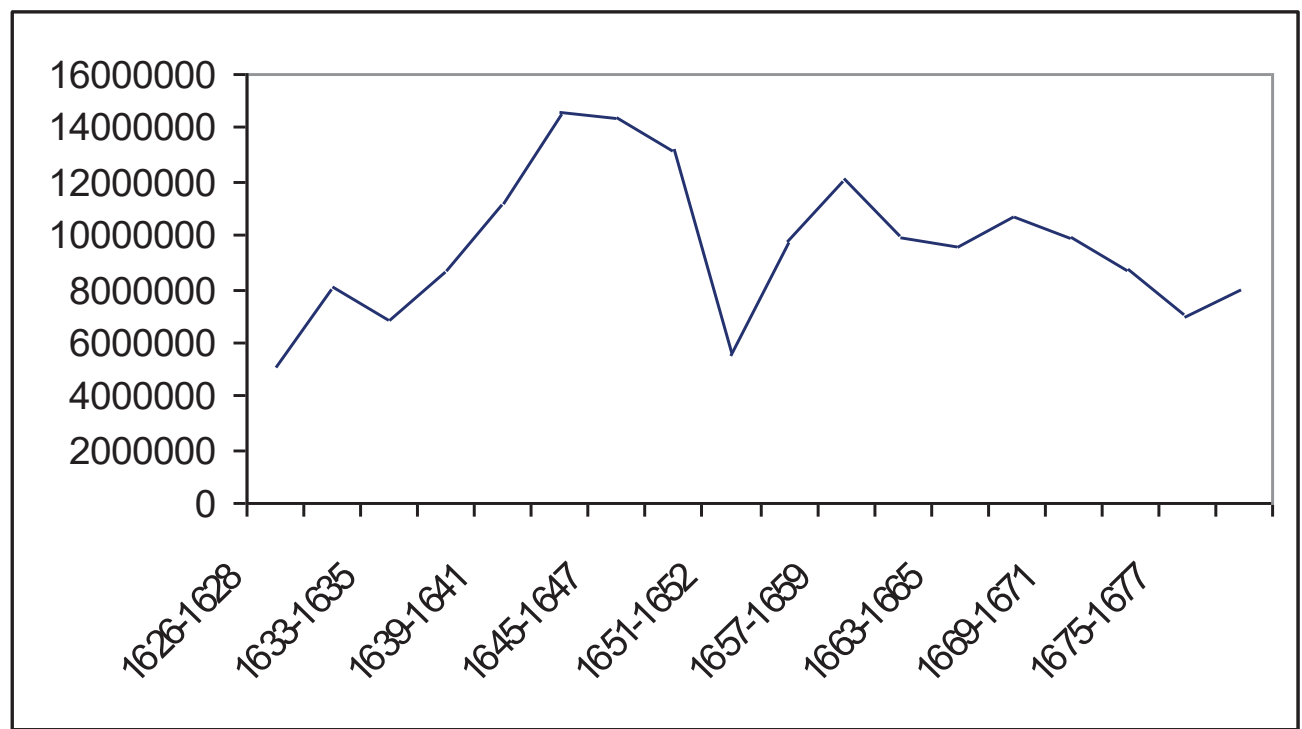

Figura 2. Curva de acuñación de plata en la ceca de Potosí en millones de pesos de a ocho reales.

Fuente: Elaboración propia del autor 
Tabla 2. Amonedación de plata de la Casa de Moneda de Potosí (1626-1680)

\begin{tabular}{|c|c|c|}
\hline Trienio & Total de Amoned. (en pesos) & I.E. \\
\hline $1626-1628$ & $5124701-4$ & 35.1 \\
\hline $1630-1632$ & 8091342 & 55.5 \\
\hline $1633-1635$ & 6804652 & 46.6 \\
\hline $1636-1638$ & 8661597 & 59.4 \\
\hline $1639-1641$ & 11243335 & 77.1 \\
\hline $1642-1644$ & 14572663 & 100.0 \\
\hline $1645-1647$ & 14339122 & 98.3 \\
\hline $1648-1650$ & 13202157 & 90.5 \\
\hline $1651-1652 *$ & 5560673 & 38.1 \\
\hline $1654-1656$ & 9805704 & 67.2 \\
\hline $1657-1659$ & 12060946 & 82.7 \\
\hline $1660-1662$ & 9906712 & 67.9 \\
\hline $1663-1665$ & 9616653 & 65.9 \\
\hline $1666-1668$ & 10651166 & 73.0 \\
\hline $1669-1671$ & 9856245 & 67.6 \\
\hline $1672-1674$ & 8669482 & 59.4 \\
\hline $1675-1677$ & 6981803 & 47.9 \\
\hline $1678-1680$ & 7932220 & 54.4 \\
\hline
\end{tabular}

* No incluye datos de 1653.

Cifras en pesos de ocho reales.

Base: Trienio 1642-1644.

Fuente: Lazo (1992)

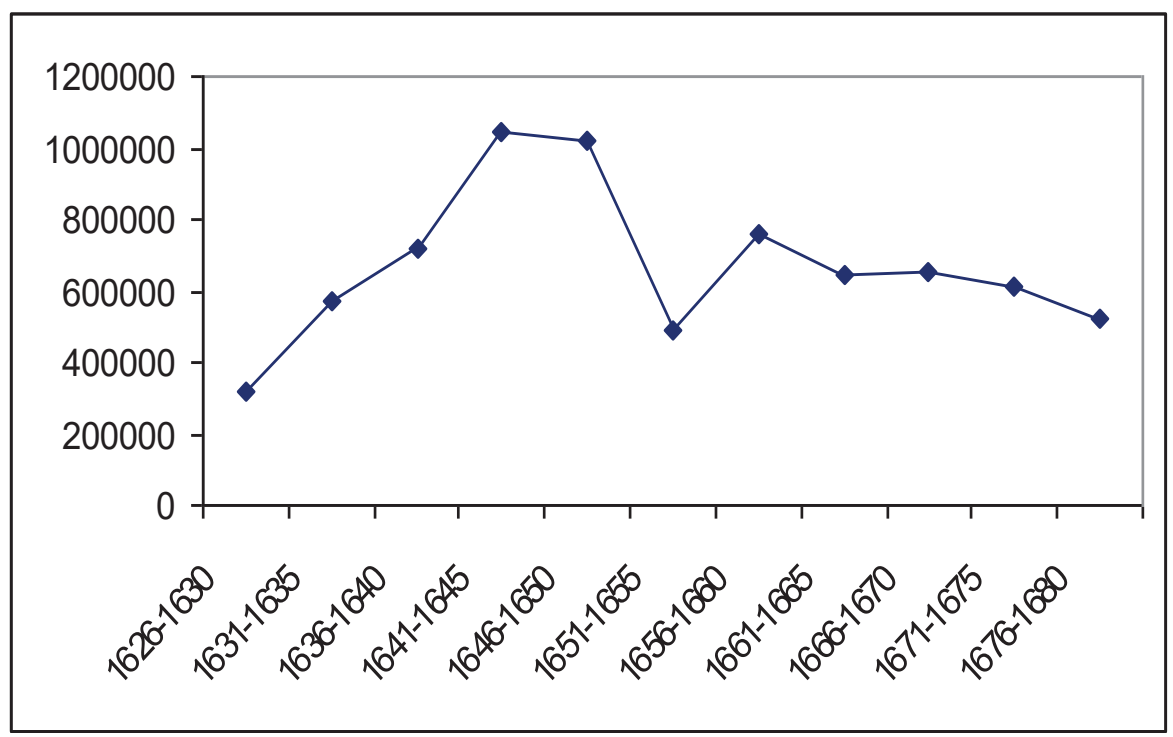

Figura 3. Reconstrucción de las series de recaudación de derechos por acuñación en la ceca de Potosí en millones de pesos de a ocho reales. 
Fuente: Elaboración propia del autor

Tabla 3. Recaudación de derechos por amonedación de plata en la ceca de Potosí

\begin{tabular}{|c|c|c|}
\hline Quinquenio & $\begin{array}{c}\text { Derechos } \\
\text { (Pesos) }\end{array}$ & I.E. \\
\hline $1626-1630^{*}$ & 321927.1 & 30.7 \\
\hline $1631-1635$ & 569831.6 & 54.5 \\
\hline $1636-1640$ & 714512.1 & 68.3 \\
\hline $1641-1645$ & 1045942.3 & 100.0 \\
\hline $1646-1650$ & 1016508.1 & 97.1 \\
\hline $1651-1655^{* *}$ & 487767.3 & 46.6 \\
\hline $1656-1660$ & 755458.5 & 72.2 \\
\hline $1661-1665$ & 644029.2 & 61.5 \\
\hline $1666-1670$ & 655238.3 & 62.6 \\
\hline $1671-1675$ & 613104.8 & 58.6 \\
\hline $1676-1680$ & 522177.1 & 49.9 \\
\hline
\end{tabular}

Cifras en pesos de a ocho reales

* No incluye el año 1629, el cual aparece sin el cobro de derechos.

** No incluye el año 1653, el cual aparece sin el cobro de derechos.

Base: Quinquenio 1641-1645

Fuente: Lazo (1992)

Dada la naturaleza del problema, es posible evaluar, en base a los indicadores señalados, el impacto que tuvo esta mengua sobre los otros sectores de la economía. Siendo así, uno de los más afectados será el del comercio, ya que como lo advertía el duque de la Palata "por los instrumentos de lo que se labra en Potosí, consta que no es suficiente para el comercio de todo el reino y que su falta en el año de armada, seca todas las venas por donde se transmina el comercio" (Hanke, 1978, p. 138). Resulta tangible entonces, que tras la merma de la minería, la economía del virreinato sufrió una intensiva depresión, que ocasionó una seria retracción macroeconómica en sus líneas centrales.

\section{- Circuitos económicos paralelos y extravío de numerario}

Los estudios de Flores Galindo señalan que el mercurio huancavelicano y la plata de Potosí fueron los motores de la vida económica virreinal, y que a partir de ellos se estableció un extenso circuito económico que comprendía Huancavelica, Lima, Chincha, Arica, Potosí y, dentro de esos territorios, Charcas, Cusco, Ayacucho y la sierra central. De esta manera, este circuito se convirtió en la ruta por la que se transportaba el mineral y los lugares que abastecían a los centros mineros con productos y fuerza de trabajo (Flores Galindo, 1977). Esta circunstancia originó que Potosí, merced a su actividad minera, se transformase en una importante y próspera ciudad, tal cual se describe en un ilustrativo testimonio, en donde se indica:

Es grande el trato que tiene de mercaderes y grandes y ricas tiendas con toda suerte de mercaderías, tiene grande correspondencia en Lima, y van de aquí muchos mercaderes a emplear a Lima y a México y a Sevilla, y echa muchos hombres muy riquísimos a vivir a España. (León Portocarrero, 1958, p. 99)

Sin embargo, la instauración de este eje económico y su posterior crisis, así como también la exclusión de la que fueron objeto los criollos de provincias, permitió el surgimiento de mercados regionales paralelos que vincularon las unidades de producción agropecuarias y textiles con 
los sectores urbanos y centros de producción minera en un todo articulado. A causa de ello, los empresarios de los circuitos económicos regionales, a medida que iban enriqueciéndose, mostraron una animadversión contra los españoles y criollos de Lima (Lazo, 1997), de suerte que, en aquel tiempo, la presencia de estos centros de producción y comercio provincianos establecieron una conexión informal con la economía mundo, participando vivamente en el comercio ilegal de manufacturas europeas y en el descarrío de las dos terceras partes de la plata producida (Lazo, 2001), por medio del cual fugaban grandes sumas de circulante en barras y monedas (Tord y Lazo, 1984).

Este socavamiento del comercio oficial y de los rubros fiscales de Real hacienda dificultó la absorción de la moneda colonial (Tord y Lazo, 1984), al ser ésta desfalcada y canalizada fuera del ámbito legal, lo que aumentó las vicisitudes del monopolio colonial (Lorente, 1870). Entre las muchas formas que existían para eludir el control y la vigilancia en el desvío de las barras, la vivencialidad de un actor anónimo de esta época revela que los transgresores idearon modos para evadir la reducción a moneda, "ya introduciéndolas en esta Ciudad [de Lima] en surrones en forma de reales, ya deteniéndolas en los caminos, o extraviando jornadas para introducirlas a horas desusadas" (AGN. D1-100-121; 1683, fol. 4), ya que, como agrega este personaje, "es tan grande el vicio ... de la codicia, que todo loo atropella" (fol. 4).

Descontando la evasión del pago de derechos fiscales, la otra razón para el ejercicio de esta práctica dañosa fue las confiscaciones de las remesas particulares efectuadas por la corona, acción que obligó a los comerciantes a esquivar el registro de sus capitales para ponerlos a buen recaudo (Suárez, 1995). Por ello, entre los diversos medios utilizados para extraer el numerario clandestinamente, en las naves que se dirigían a Portobelo, estaba el que los dueños de los bultos, aprovechando que no se revisaba las cajas que llevaban, hacían "de la pasta de piña ... barretones pequeños, y de la plata labrada, planchas, y ajustan el pesso en caxones del tamaño de reales, los disimulan y passan como si lo fuesen" (AGN. D1-83-1936; 1683, fol. 3). Este acto contravenía la disposición de que la plata para "ser de usso ... universal del comercio ... se reduzga a moneda" (La Palata, 1859, p. 215).

Sobre este asunto, la huida del circulante y el ingreso de contrabando por los puertos intermedios correspondientes a cada región, como táctica ilegal de relación con los mercados productores, constituyó un elemento disruptivo que dislocó la estructura de los circuitos comerciales lícitos al interior del virreinato (Sempat, 1982). En consecuencia, la presión de estos polos para el desarrollo de la minería bajo peruana tiene como fruto la revaluación del marco de plata y la proliferación de la minería regional. La prosperidad conseguida por este medio se expresó no solo en el desarrollo de las haciendas y su captación desmedida de yanaconas, sino también en una contracción de los servicios tributarios y en una acumulación extraordinaria de capitales, que dio lugar a su atesoramiento en algunos casos, y en otros a su extravío a través del tráfico comercial ilícito (mercancía llegada de Cartagena y Ecuador que entraba por Paita; y asimismo por Arica, por donde se internaba las mercaderías de contrabando procedentes de Chile y Buenos Aires).

Esta oposición a la bisagra Lima-Potosí provocó simultáneamente la declinación del mismo y el desequilibrio del ordenamiento fiscal. Este momento descentralizador se produce no solo porque el centro deja de apretar, como sostiene Contreras (2002), sino también porque la periferia busca liberarse. Prueba de ello son estos circuitos de producción y comercio que desarrollaron las regiones, que al competir con la capital los hizo menos dependientes de ella. 


\subsection{Medidas reordenadoras}

Dado que la política económica metropolitana presentaba deficiencias, fue necesario reajustarla. En tal sentido, al virrey duque de la Palata le fue encomendado el restablecimiento del orden económico legal y la restitución de su hegemonía (Lazo, 2001). Por lo dicho, en la segunda mitad del XVII, el gobierno de Lima dictó una serie de medidas tratando de reencausar la riqueza que las provincias extraviaban (Lazo, 1997). Con la dación de estas acciones se apuntaba a mantener la institucionalidad y el ordenamiento del Estado colonial, a fin de restablecer la maximización de los beneficios que la metrópoli obtenía de estas posesiones.

En este marco, el objeto de estas disposiciones se orientó a asegurar la provisión económica de Lima, tendiendo a incrementar los cargos de las cartas cuentas provincianas y las consiguientes remisiones hacia la capital, de modo que ésta y Madrid obtuvieran una participación más pingüe de las riquezas del país (Lazo, 2001). A decir verdad, la Palata intensifica el papel rector de la economía desde Lima, procurando contrarrestar el despegue de los desarrollos regionales, que les quitaban el poder a los limeños y se lo daban a los criollos de provincias. Especialmente, se propone como objetivos: evitar el comercio de mercaderías francesas; restablecer el amonedaje en las cecas de Lima y Potosí; defender el comercio importador lícito; impedir el extravío de la plata piña; y cobrar los derechos reales (AGN. D1-100-121, loc. cit., fol. 4v).

Dando cumplimiento a su misión, el virrey adopta las siguientes orientaciones para someter la economía provinciana al control de Lima: la reapertura de la casa de moneda de Lima (1684) y la obligatoriedad de realizar el comercio de Portobelo exclusivamente con monedas acuñadas. La reducción del quinto real al veinteavo, para incentivar el quintaje de las pastas preciosas producidas en los circuitos regionales del Bajo Perú e impedir su extravío. Y, en último término, la reinserción de las regiones económicas provincianas al área del control de la economía oficial limeña y a su eje Lima-Potosí y Lima-Portobelo-Sevilla (Lazo, 2001). La aplicación de esta política se tradujo en: la reapertura de la ceca limeña, la elevación del peso ensayado, sanciones para prohibir la extracción de numerario, la construcción de las murallas de Lima, el reordenamiento de la mita minera y la protección a los indios.

\section{- Reapertura de la casa de moneda de Lima}

Luego de su llegada al gobierno, la Palata resucitó la ceca limeña en 1682, entidad fundada en 1545 y supresa en 1572 (Del Busto y Lohmann, 1994). Esta reapertura estaba imperiosamente reclamada por las necesidades de la administración y del comercio, porque después de despachada la armada para Panamá escaseaba en la ciudad el numerario para los pagos de gobierno y giro mercantil, consumiéndose lo que venía de Potosí en el pago de situados, azogueros de Huancavelica $\mathrm{y}$ otras atenciones que no era posible satisfacer en barras (Lorente, 1870).

Por esta razón, algunos memoriales de los vecinos de Lima dirigidos al duque lo instaban a que: «repare el último bayben en que consiste la ruina de este Reyno» (AGN. D1-100-260, s/f, fol. 1v), recomendándole reabrir la «Real Cassa de Moneda, la más estimable joya de su adorno, [en la que] ha de tener parte en la instauración y adelantamiento de sus labores» (fol. 1v). Esta realidad convenció al virrey de la exigencia de reabrir la ceca limeña, situación que él mismo reconoce en sus memorias cuando señala: «Luego que llegué a este gobierno ... comprehendí que sin perjuicio de la de Potosí, se podía y combenía fundar Cassa de moneda en esta ciudad» (La Palata, 1859, pp. 138-139).

El virrey trasladó esta petición al rey en despacho del 20 de noviembre de 1682 (La Palata, 1859), demostrando lo provechoso que sería para el erario la acuñación de moneda en Lima, 
desde que no era posible enviar las barras a la de Potosí y, además, por el frecuente contrabando que ello generaba (Garland, 1908). Este argumento tenía su fundamento en que, con la fundación de casa de moneda en la capital: «toda la pasta de plata que produciessen los minerales del reyno, y [que] huviesse de salir del para la España y otras partes, no saliesse sino fuese labrada en monedas en las Cassas de Potossí y Lima» (AGN. D1-100-91, 1682?, fol. 1).

De este modo, con el funcionamiento de la Casa de moneda, el virrey pretendía debilitar el control que tenían los aviadores vinculados al circuito potosino en la circulación del capital comercial y, al mismo tiempo, estimular la movilidad del metálico (Gonzáles, 2000). Es así que, venciendo la oposición de Potosí y Sevilla (Lorente, 1870), gracias a los esfuerzos del duque de la Palata y a mérito de la autorización regia del 6 de enero de 1683, en el mes de diciembre de ese año la ceca de Lima volvió a funcionar, y esta vez de modo definitivo (Lazo, 1992).

\section{- Elevación del peso ensayado}

Hasta antes de que se produzca la reapertura de la ceca de Lima, los ensayados mayores no tenían precio fijo, ya que, como lo registran los testimonios de esta época, en el tiempo en el que no había flota para Portobelo se vendía a 138, 139 y 140 pesos de a 9 reales; pero conforme se aproximaba la partida de la armada, subía a 141, 142, 143 y 144, cambiándose éstas en la misma feria al valor de 148 pesos: «siendo este precio tan excessivo para labrar monedas» (AGN. D1100-58, s/f, fol. 1), que a los mercaderes sevillanos no les era posible comprarla, por cuya causa: «las extraviaban los cargadores en perjuicio de la corona» (fol. 1). Estos extravíos provocaron una elevación del precio de la plata piña y la barra, que eran adquiridas por los comerciantes franceses a cambio de sus mercaderías, «cuyo augmento en una y otra especie ha motivado a los vasallos a obrar con infidelidad, negándose a pagar los derechos de su Majestad» (AGN. D1-100165, s/f, fol. 1).

Esto se explica en razón de que todas las barras que se producían en los diferentes centros mineros del virreinato (exceptuando los de Potosí) eran tenidas por los comerciantes como mercancías, ya sea con el fin de llevarlas a la feria de Portobelo y venderlas al precio de 148 pesos, de a 9, o bien para extraviarlas por otras vías (AGN. D1-100-59, s/f, fols. 3-3v). Para evitar este desvío de piñas y barras, la corona ordenó que paralelamente al cobro del quinto real se cobrase el derecho de señoreaje, con lo cual se pensó que se contendría esta desviación (AGN. D1-100-165, s/f, fol. 1).

De igual modo, cuando se reabrió la casa de moneda de Lima se dispuso que los ensayados mayores a 450 maravedís, que se contienen en el marco de barra, se paguen al precio fijo de 144 pesos de a 9, por cada 100 ensayados mayores, «por ser este el precio más superior a que se puede comprar el marco de barra para reducirse a moneda» (AGN. D1-100-58, s/f, fol. 1), operación destinada a mejorar los ingresos de los mercaderes de la plata con el objeto de motivarlos a amonedar mayores cantidades de barras. Asimismo, en lo concerniente a las barras de las cartas cuentas, se mandó a los oficiales reales, por decreto del duque de la Palata, que se cobrase los ensayados mayores a los mercaderes de la plata de la casa, al valor de 143 pesos de a 9, medidas con las que también se buscaba contrarrestar el extravío de las barras y piñas: «en utilidad de los reales haveres y causa pública» (AGN. D1-100-58, s/f, fol. 1).

\section{- Medidas para impedir la extracción ilegal de monedas}

La Palata, comprendiendo su misión en el campo económico, y con el objetivo de impedir la extracción ilegal de numerario, se avocó a la ejecución de tres tareas inmediatas: el monitoreo de las actividades de recaudación, el control de los caminos y la dación de normas para 
obligar al amonedaje de barras argénteas. En cuanto a lo primero, ejerció una atenta vigilancia sobre la recaudación, cuidando que los oficiales reales le diesen razón todos los meses de sus respectivas cajas, recomendándoles expresamente: «veléis continuamente en el aumento y mexor administración de la Rl. Hazienda ... procurando que se quinten todas las Piñas que se sacaren, de suerte que no se extravié cosa alguna deste genero» (BNP, Ms., B-295, 1686), medida con la que logró al mismo tiempo conocer los fondos existentes y sostener el celo de aquellos empleados (Lorente, 1870). En este sentido, se mandó que los oficiales reales de todas las cajas remitiesen a través del correo la información tocante a las barras fundidas, los dueños a quienes pertenecían y los responsables de conducirlas a la ciudad (AGN. D1-89-2033, s/f, fol. 3).

De igual modo, para que el tribunal de cuentas se pusiese al corriente nombró cuatro contadores ordenadores con el mismo sueldo que los demás, y pagadero con los alcances que descubriesen. De esa manera pudo conseguir, por cierto tiempo, activar las entradas y tener la contabilidad más arreglada (Lorente, 1870). Además, en las Ordenanzas para corregidores se dispuso que, en los lugares donde existiese minas de plata y oro, los corregidores debían notificar a los mineros la obligación de que cada quince días manifiesten la cantidad de mineral que hubiesen beneficiado en piñas, planchas y machacados, debiendo luego enviarlos a quintar con certificación suya (BNP, Ms., C-4644, 1687, fol. 22v-23). Para tal fin, cada uno de los corregidores registraba en un libro las partidas de plata que los mineros manifestaban, declaración que cada seis meses debía ser remitida a los oficiales reales del distrito donde estuviere sujeto, para que a través de un cruce de información: «se bea y coteje los que an dexado de quintar y se proceda contra ellos» (BNP, Ms., C-4644, 1687, fol. 23-23v).

En relación a lo segundo, satisfecho el deber de cuidar las entradas, el virrey mostró suma diligencia para evitar las salidas irregulares (Lorente, 1870). Para el efecto, tal parece que, haciendo eco de un anónimo memorial que sobre el extravío de plata piña recomendaba revisar las cargas y petacas transportadas por los correos, así como a toda persona que saliese o llegase a la capital (AGN. D1-100-32, s/f, fol. 1), dispuso por delegación de funciones que el superintendente de la casa de moneda de Lima para el control de la entrada y salida de barras coloque guardas en los caminos, quienes debían dar parte del ingreso de las mismas (AGN. D1-89-2033, s/f, fol. 3). Igualmente, se previno en las funciones del escribano de la casa de moneda, que éste al tener noticias del arribo de las cartas cuentas o barras de particulares, saliese a recibirlas a los caminos y accesos de la ciudad, y que tome declaración jurada a los dueños o arrieros, del número de barras transportadas, notificándoles la obligación de llevarlas a la casa de moneda, informando luego de estas diligencias al superintendente de la casa (AGN. D1-89-2033, s/f, fol. 3).

Asimismo, por bando publicado el 3 de diciembre de 1683, se nombró a Juan Jiménez Lobáton, superintendente de la casa de moneda, como juez privativo con plenos poderes para el conocimiento de las causas en torno al desvío del numerario en Lima, el Callao y otras jurisdicciones. Contando entre sus facultades, el poder nombrar ministros y otras personas para que se desplacen hacia los lugares: «donde se tenga noticia que se saca o puede sacar de este Reyno la plata en pasta, para la aprehención de ella o a otros efectos que parecieren necessarios» (AGN. D1-83-1936, 1683, fols. 3v-4), debiendo las demás justicias y oficiales reales informarle de la ejecución de acciones, en cumplimiento de lo que disponía esta provisión. En caso de transgresión, los infractores se hacían merecedores a las penas impuestas en la Real Cédula del 13 de diciembre de 1660 y 23 de junio de 1680, que tratan de los extravíos de plata y oro respectivamente (AGN. D1-83-1936, 1683, fol. 3v).

En lo concerniente al último punto, el virrey la Palata, de un modo terminante, prohibió los giros del comercio internacional en barras de plata (Lazo, 1992), «porque en este punto - 
decía él-, consiste el remedio tan deseado por el bien de la Monarchia, para que no passen a los estrangeros sin dexar algún útil en el comercio de España» (La Palata, 1859, pp. 154-155). Mandato que se efectivizó el 3 de diciembre de 1683, mediante la publicación de un bando, en el que se impide sacar la plata en pasta fuera del virreinato, sin ser antes previamente amonedada para poder comerciar con ella (AGN. D1-83-1936, 1683, fol. 3v).

Dicho bando advierte también que durante el tiempo anterior al envío de la armada a Panamá, era posible labrar la plata en pasta existente en Lima, determinando así que todos los poseedores de barras hagan manifestación de ellas, por medio de una declaración jurada ante el superintendente de la casa de moneda, indicando el número, peso y ley de cada barra; todo ello dentro de un plazo de 20 días posteriores a la publicación de este bando, so pena de perderlas por decomiso (AGN. D1-83-1936, 1683, fol. 2). También, con el fin de evitar el fraude, se mandó: «reconocer en tiempo de Armada y en los vajeles que salieren antes para Panamá, Valles o Guayaquil, y lo mismo por tierra, todo género de caxones, petacas, baúles y otras piesas, y que los Maestres han de dar cuenta de cuyos son, con marcas y peso de cada pieza» (AGN. D1-831936, 1683, fol. 3).

No obstante, en situaciones coyunturales muy concretas se permitió la infracción de este mandamiento, al extremo que al rey no le quedó más remedio que autorizar a su representante a establecer excepciones cuando resultare preciso (Real Cédula del 1 de mayo de 1684), y admitir al comercio de Lima embarcar barras hasta un 10\% del valor de su giro monetario (Lazo, 1992). En otras ocasiones, estando próxima la salida de la armadilla del mar del sur, el mismo gobierno colonial, para aprovisionar de monedas al comercio, salió a comprar las barras, como ocurrió en 1684 en que se dispuso a través de bando del 18 de diciembre de dicho año: «que todos los que tuvieran barras y no pudieran reducirlas a moneda antes de la salida de la Armada, las traigan a las caxas Reales a donde se las pagaran de contado en reales, al precio que se venden en la plaça» (AGN. D1-98-2223,1684, fol. 1).

\section{- Construcción de las murallas de Lima}

Tomando como referente que el Perú, durante todo el siglo XVII, habría de sufrir los riesgos y ataques consiguientes a su debilidad colonial y a la escasa protección de la metrópoli, fue tomando cuerpo la idea de amurallar la ciudad de Lima. Este proyecto logró efectivizarse en 1684. En este sentido, Guillermo Lohmann (1964) indica que, ante la presencia visible e inmediata de piratas y corsarios, tomó cuerpo la inextinguible aspiración de construir defensas militares que pusieran a Lima a cubierto de la codicia que despertaba la concentración en la ciudad de las remesas de metales preciosos destinados a embarcarse con rumbo a la metrópoli.

Aunque técnicamente las murallas no poseían troneras o portañolas para plantar piezas de artillería, servían para el propósito de proteger la ciudad. Pero, además, acorde con las medidas económicas adoptadas por el virrey, las murallas tuvieron otro fin, el cual fue evitar el contrabando de mercaderías y monedas. Esto queda confirmado en las razones que da la Palata para amurallar a Lima, cuando éste manifiesta: «la grande obra de las murallas y fortificación de esta ciudad ... [tiene por intención] assegurar en ella los inmensos thessoros que se recogen en esta universidad [o universal] caxa de los Mundos» (La Palata, 1859, p. 426).

Esta aseveración es un indicio testimonial que, a la luz de la historia económica, nos permite asegurar que el amurallamiento de la capital, descontando su carácter defensivo, también se hizo para efectivizar varias medidas económicas que tomó el gobierno colonial, como la prohibición de llevar barras de plata a la feria de Portobelo. Ello estaba relacionado al desarrollo de un intenso 
tráfico ilegal de barras sin quintar, que afectando al fisco y al comercio oficial, eran utilizados para comprar mercaderías de contrabando, que luego eran introducidas clandestinamente en el virreinato.

Sin duda, las murallas fueron un medio eficaz para perseguir a los traficantes, tanto de mercancías como de barras que no pagaban el quinto y el señoreaje. Por lo que, a partir de su edificación, toda barra que entraba o salía de Lima era objeto de un minucioso registro y datación que debía contar con la documentación del caso, so pena de hacerse acreedor del decomiso y la aplicación de las sanciones penales correspondientes. De más está decir que el amurallamiento de la ciudad cumplió con la misión de hacerle frente al contrabando, el déficit fiscal y el extravío de barras de plata no registradas (Palza, 2008).

\section{- Reordenamiento de la mita minera}

Como bien indica Enrique Tandeter, las mitas mineras constituían el subsidio que las empresas mineras recibían para hacer rentable la producción de plata, ya que sin ella la extracción del mineral argénteo habría dejado de ser rentable y los campamentos habrían sido abandonados. El mismo autor explica que sin este aprovisionamiento de plata el virreinato se habría visto imposibilitado de mantener el comercio ultramarino, perdiéndose así vínculos y ganancias para la metrópoli (Tandeter, 1992). Por ello es que, en lo que atañe al régimen mitayo, la Palata, antes de partir al Perú, recibió expresas instrucciones que le recomendaron: «que luego que entrasse en estos cargos tubiesse por primer cuidado la reintegración de la mita de Potossí» (La Palata, 1859, p. 237). Sin embargo, dice él: «halle tan dificultoso el remedio como urgentes los motibos de intentarlo» (La Palata, 1859, p. 426).

Esta complicación radicaba, como advertía el virrey, en el: «sumo desorden [que] ha muchos años que se hallan las provincias del Perú» (La Palata, 1859, p. 242). Por este motivo, según su percepción: «lo que puede discurrirse es que no se ha minorado el gentío ... sino que se han retirado de sus poblaciones» ( p. 242). Es decir, la Palata consideraba que la disminución y la falta de indios en las 16 provincias afectas a la mita minera las había causado la facilidad con la que los naturales se pasaban a las otras 14 provincias exentas (La Palata, 1859).

En tal sentido, viendo que era imposible hacer retornar a esta población a sus lugares de origen, y con el fin de evitar que se repita el mismo fenómeno, estimaba que: «no queda otro remedio ... que el de la numeración general en el padrón, siguiendo la diligencia el mismo camino que han tomado los Indios para la aculturación» (La Palata, 1859, p. 242). Con este empadronamiento se buscaba subsanar dos cosas: primero, el que dejen de pagar tributos los indios presentes por los ausentes y los vivos por los difuntos; y segundo, acrecentar los caudales del fisco real, defraudado por la fuga de los indígenas a otras provincias (La Palata, 1859). En estas condiciones, desde su llegada a Lima en noviembre de 1681 y a lo largo de 1682, el duque y su equipo de gobierno trabajaron en la definición del proyecto censal (Gonzáles, 2000).

Una vez tomada esta resolución, el virrey dispuso que los corregidores sean los encargados de ejecutar esta operación, quienes para hacer más fácil su labor debían contar con la asistencia de los sacerdotes. En virtud de ello, éstos deberían exhibir sus libros o padrones de confesiones, bautismos y matrimonios. Con este propósito, el duque de la Palata escribió cartas a todos los obispos, pidiéndoles que soliciten a los párrocos los padrones de sus feligreses y que luego se los remitieran; asimismo, también hizo lo propio con los religiosos, recordándoles que, como sacerdotes y vasallos del rey, estaban en la obligación de apoyar a los corregidores, mostrándoles los libros sin reserva alguna (La Palata, 1859). 
Dispuestos así los pormenores, se fijó como el día señalado para iniciar la numeración el $1^{\circ}$ de octubre de 1683, tarea que concluyó en 1688, luego de seis años (La Palata, 1859). Sin embargo, la valoración del censo quedó en tela de juicio, pues de acuerdo con los expertos, los padrones contenían abundantes anomalías. Para empezar, no se desarrolló simultáneamente, como estaba previsto, y su dilatada prolongación hizo visible la existencia de registros duplicados; asimismo, el formato de registro hacía imposible identificar muchos ayllus. Por último, la fiabilidad del censo había descansado sobre curacas y gobernadores, quienes tuvieron a su alcance el ocultamiento de indios (Gonzáles, 2000).

En el mismo sentido, se pronuncian los investigadores Raquel Gil, Lia Oliveto y Fernando Longhi(2015), quienes encuentran que la metodología del censo fue tan complicada y contradictoria que casi garantizaba los errores y las dificultades en su interpretación. Ellos indican que los indígenas debían ser ingresados en uno de ocho libros según su status: originarios presentes y sus familias, ausentes con destino conocido, ausentes desaparecidos, forasteros, yanaconas del rey, mitimaes, yanaconas de chacras y yanaconas de iglesias y conventos. El resultado, conforme con su análisis, fue muy diverso, no solo por la forma en que se agrupó a la población, sino también por los datos que se consignaron para cada uno de los empadronados, de acuerdo con los criterios utilizados por el visitador de cada provincia.

Estas deficiencias no fueron del todo ignoradas por el duque, por lo que casi se vio enfrentado con los miembros de su propio equipo de gobierno, quienes criticaron las disposiciones económicas de la numeración. Pese a ello, la Palata decidió, contra viento y marea, acelerar la ejecución del proyecto. Así, cuando ésta finalizó en 1688, este representante real apresuró la reimplantación de un repartimiento laboral masivo para la minería potosina (Gonzáles, 2000). Con la conclusión del censo, el virrey convocó a una junta de asesores, que con la información cuantitativa obtenida, estableció el repartimiento de indios para la mita de Potosí en 20829 naturales, cifra a la que se le asignó 10402 indios más a los 10427 que antes tenía (La Palata, 1859). En esta dirección, se agregaron nuevas provincias a las anteriormente destinadas a Potosí, incluyendo a los indios forasteros y yanaconas que se hallaban en dichas provincias.

En estas circunstancias, despachadas a todas las provincias las provisiones de retasa y mita, se dejó sentir la voz en contra de los corregidores, curas y curacas, quienes estaban inconformes con esta distribución, ya que los afectaba en sus intereses económicos, lo que los convertía, como anotaba la Palata, en «los mayores enemigos de este negocio, porque todos interessan en que el indio no salga para la mita, por servirse de él en sus granjerías» (La Palata, 1859, p. 253). Esto obligó a que el virrey despachase a todo el virreinato, el 29 de abril de 1689, la difusión de unas «Advertencias para la retasa y repartimiento de mitas de Potosí» (La Palata, 1859, p. 264), en donde señalaba que: «si cada uno tira de la manta del indio para cubrirse, solo la harán pedaços y quedarán todos desnudos» (p. 264). De esta manera, les hacía ver a los criollos de provincias, la inconveniencia de su rebeldía, que a la larga no los beneficiaría ni a ellos ni al gobierno; lo que en este caso significó un duro golpe para los regionalismos provincianos, al privarlos de la mano de obra que necesitaban en resguardo del circuito oficial.

\section{- Protección a los indios}

En el siglo XVII, las crónicas de denuncia social aparecen como un grito de alerta, llamando la atención sobre la destrucción de la población aborigen, un hecho que a las claras atentaba contra los cimientos del régimen colonial. Esta circunstancia va a crear una conciencia sobre la necesidad de conservar al indio, por lo que representaba su trabajo para el erario real (Lazo, 1975). Los ejemplos ocasionales de estas denuncias sobre las tropelías cometidas con los indios, 
como consecuencia del incorrecto accionar de los funcionarios (corregidores, encomenderos, doctrineros y curacas) (Lazo, 1975) llegaron incluso hasta oídos de la corona, razón por la que el rey se pronuncia a través de la Real Cédula del 22 de febrero de 1680, en la que declara tener conocimiento de los maltratos que sufrían los naturales en los obrajes, y convencido de las: «muchas vexaciones que llegan a ser yntolerables, que es la total destrucción de los indios, y de sus pobres caudales, mugeres y familias» (AGN. Sup. Gob., GO-BI 1, Cj. 24, Dto. 56, 1681, fols. 2-2v). Ordenaba que el virrey ponga énfasis en la labor de protección de los naturales, y en que se le haga saber: «que excesos se causan en las labores de todos los obrajes» (AGN. Sup. Gob., GO-BI 1, Cj. 24, Dto. 56, 1681, fol. 3).

Asimismo, con el ánimo de aminorar los agravios a los indios, el virrey separó los cargos de protector y juez de censos, que estaban reunidos en una misma persona, con inminente riesgo de malversar la hacienda de los indígenas. De modo similar, en Potosí ordenó la separación del puesto de protector y juez del hierro (Lorente, 1870). Casi al mismo tiempo, el 20 de febrero de 1684, el duque de la Palata emitió la ordenanza general a favor de los indios y adoctrinamiento de ellos, documento compuesto por 33 disposiciones, con el fin de evitar: «los agravios que generalmente padecen los Indios de este Reyno ... por medio y mano de los mismos que los goviernan y administran, assí en lo espiritual, como en lo temporal» (La Palata, 1684, p. 135).

Entre otras cosas, ésta y otras ordenanzas disponían que los gobernadores, corregidores, tenientes y curacas no consientan los abusos cometidos contra los bienes y personas de los indios, efectuados tanto por laicos como religiosos regulares o seculares (Ballesteros, 1752). Ya que como él mismo lo indica en su escrito del 5 de marzo de 1684 se debía buscar el: «mayor alivio destos miserables, por la promta obediencia a las Reales Ordenes, con que su Majestad ... nos tiene prevenidos a los superiores, y por la conmiseración a que la natural pusilaminidad de estos desvalidos nos executa» (BNP, Ms., B-1683, 1684). Ordenando así que estas autoridades: «tengan particular atensión al buen tratamiento de los caciques y de los demás yndios, assi en palabras como en obras ... procurando que por ninguna manera tengan ... atrevimiento a hacerles mal ni a desirles palabras afrentosas» (BNP, Ms., B-4644, 1687, fol. 13-13v).

En otros casos, la Palata expidió provisiones, como ocurrió el 17 de abril de 1687, por las cuales mandaba que los indios residentes en los obrajes fuera de su lugar de origen paguen el tributo solo en plata y no especies, como pretendían hacerlo algunos corregidores, quienes no tomaban en cuenta que muchos de los aborígenes que laboraban en los obrajes eran forasteros que se sustentaban solo con el jornal que se les pagaba (AGN. Sup. Gob., GO-BI 2, Cj. 63, 1687, fols. $2 \mathrm{v}-5 \mathrm{v}$ ). Por otro lado, el gobierno de Lima, buscando congraciarse con la población india, estableció una tasa general de salarios, homologando el salario de mingados y mitayos mediante la concreción de un jornal de 4 reales (Tord y Lazo, 1984). Homologación que quedó determinada en el arancel de 1687, el mismo que revela dos realidades: un servicio mitayo oficial al cual se le reconocía un haber de subsistencia servil; y un servicio de alquilas, que mediante el salario, oficialmente se equiparaba con la servidumbre mitaya (Tord y Lazo, 1984).

\subsection{Resultado de las reformas}

Con la aplicación de las reformas, el gobierno de Lima logró reencausar la economía regional. Sin embargo, las medidas no fueron suficientes porque provocaron que los conductores de la economía bajo peruana protestaran contra el centralismo del gobierno central (Lazo, 2001). En ese interín, el mandato del duque de la Palata concluyó en septiembre de 1689. Mientras esperaba el arribo de su relevo, Melchor Portocarrero Lasso de la Vega, conde de la Monclova, quien provenía de México (Nueva España), la Palata se apresuró a acelerar la aplicación de lo que quedó 
pendiente de su programa político, pues temía que su sucesor objetase, total o parcialmente, concluir un proyecto inacabado, sobre el que pesaban numerosas críticas. No obstante, al finalizar la administración del duque, quedaron sin culminar algunas de estas diligencias, relativas a la difusión y ejecución de las nuevas tasas (Gonzáles, 2000).

Una vez que el conde de la Monclova asumió las funciones de gobierno tuvo que enfrentar una crisis de orden político, económico y social generada por las reformas implementadas por su antecesor (Gonzáles, 2000). La gravedad de la crisis quedó evidenciada, sobre todo, en el rechazo en la redistribución de la renta fiscal. Así lo manifestaron los cabildos del interior cuando, a propósito del término del mandato del duque de la Palata, remitieron sendos informes al nuevo virrey recalcando el olvido de que eran objeto y, proclamando, en un acto de insolencia y de rebeldía, que a partir de la fecha se convertirían en celosos fiscalizadores de la labor del gobierno (Lazo, 2001). El mismo sentir quedó impreso en una multitud de escritos y protestas que, desde el otoño de 1689 habían afluido a Lima desde todos los rincones del sur andino. Esta oposición también fue expresada por los obispos del Cusco y La Paz, así como por el arzobispo de la Plata, quienes mostraron su preocupación y desacuerdo con este programa, a la par que advertían sobre las nefastas consecuencias que esto traería en la explotación de la masa laboral indígena y la despoblación de las haciendas agrícolas mercantiles (Gonzáles, 2000).

Estas dificultades conllevaron a que el virrey conde de la Monclova decida aplazar la continuación de las reformas. Mientras tanto, solicitó informes para evaluar la magnitud de la crisis. Messía, presidente de la Audiencia de Charcas, en su informe del 22 de marzo de 1690, enumera los defectos y secuelas negativas de la política del virrey anterior, que resume en: colapso de la recaudación fiscal, incremento en las quiebras en los enteros de mita, incapacidad de proceder al reparto de tierras para asentar a los forasteros y, en definitiva, la absoluta incompatibilidad del proyecto con la realidad de la articulación social y económica entre el orden colonial y el mundo indígena del sur andino. Estas son las razones por las que recomienda la suspensión del proceso iniciado en 1689 (Gonzáles, 2000).

Con estas observaciones, el virrey procede a ordenar una minuciosa revisión de la política desplegada por su predecesor. Casi al finalizar 1690, la Monclova abordará la solución de la crisis abierta por la retasa y el nuevo repartimiento de la mita. En diciembre del mismo año, requiere una vez más informes de las autoridades altoperuanas sobre el alcance de las repercusiones que se estaban produciendo. Esta nueva encuesta, dirigida al arzobispo y presidente de Charcas, y a los obispos de La Paz, Cusco y Santa Cruz de la Sierra, iba encaminada a disponer de información actualizada, que constituiría el elemento básico de la proyectada política revisora de la Junta, convocada en ese mismo mes de diciembre para proceder, durante 15 meses, a la valoración de los procesos sociales y económicos desarrollados en el Alto Perú a partir de 1689 y del rol jugado por el sistema de repartimientos mineros, así como, de manera concluyente, a negociar las medidas necesarias para reequilibrar la situación tras las alteraciones surgidas el año anterior (Gonzáles, 2000).

La Junta fue convocada el 12 de diciembre de 1690 con el objetivo explícito de revisar las medidas de la administración anterior. Pero, implícitamente, dentro de ella existía un espíritu abolicionista respecto a la dinámica y los efectos de los repartimientos de trabajadores indígenas para la explotación minera. Bajo este ambiente, el 18 de diciembre de 1690 la junta inició sus reuniones. La primera fase de la junta se extendió hasta el 12 de mayo de 1691. Durante ese lapso se celebraron un total de 33 sesiones de carácter evaluativo; en el transcurso de esos cinco meses, los integrantes de la junta repasaron toda la documentación relativa a la gestación, desarrollo y consecuencias del programa de tasas y repartimientos instaurados por el duque de la Palata: 
los decretos de 1689, las representaciones de los curacas y corregidores de todas las provincias, los informes sobre la industria potosina, algunas visitas de minas e ingenios en esos años y las distintas comunicaciones remitidas por las autoridades civiles y religiosas de Charcas (Gonzáles, 2000).

La revisión de esa amplia relación documental proporcionó el material necesario para proceder a elaborar un expediente. El 19 de mayo de 1691, la Junta inició la que constituía su segunda y decisiva etapa: las reuniones deliberativas de las que habría de extraerse una resolución sobre los problemas originados alrededor de la mita potosina. En esta segunda fase, la composición de la junta se vio aumentada, debido a su carácter resolutivo, por el conjunto de integrantes de la audiencia: el propio virrey y todos los oidores (Gonzáles, 2000). Resultó determinante en esta etapa de deliberaciones la actuación del fiscal Matías Lagúnez, quien en su discurso sobre la mita de Potosí, alegato de más de mil doscientos folios, se manifestó contrario al trabajo forzado de los indios. El 23 de abril de 1692, tomando en cuenta la recomendación del fiscal, la junta se pronunció a favor de la abolición de casi todas las reformas de 1689. Cuatro días después, el 27 de abril, se promulgó en Lima una provisión impresa que recogía los acuerdos alcanzados por la Junta, con lo que quedó oficialmente revocada la política reformista llevada a cabo por la Palata en el sur andino (Gonzáles, 2000).

$* * *$

Las medidas adoptadas para restablecer el eje económico oficial del Perú colonial, pese al empeño puesto por el duque de la Palata, como es de suponer, resultaron tardías, puesto que el desarrollo económico no oficial criollo provinciano, hacia fines del siglo XVII, había conseguido dañar irreversiblemente al oficial criollo limeño. Esta desestabilización se manifestó en la desarticulación del orden laboral, promoviendo la conversión de mitayos en yanaconas. Su oposición al eje económico Lima-Potosí creó circuitos regionales de producción y comercio dotados de una minería propia. Esta fue una perturbación del ordenamiento fiscal, al eludir de modo sistemático el pago del quinto real, la alcabala, el almojarifazgo y el señoreaje. Y en el orden político, creó un concepto de patria Perú para los peruanos (Lazo, 2001).

De manera que la política del virrey para flexibilizar sus más severas medidas, a fin de lograr la reinserción de los regímenes económicos provincianos al área de control de la economía oficial limeña y a su eje Lima-Potosí y Lima-Portobello-Sevilla, muy pronto quedo detenida. Esto debido a que los circuitos provincianos establecieron una suerte de relación económica informal con la economía mundo, participando activamente en el tráfico ilegal de manufacturas europeas y en el extravío de las dos terceras partes de la plata producida (Lazo, 2001).

La marginalidad respecto a Lima y al gobierno central caracterizó su existencia y su devenir como empresarios provincianos. No obstante, todos ellos constituían un cuerpo económico que subsidiaba la economía de Lima, a través de la vía tributaria fiscal y del comercio no equivalente. Bajo el mandato del virrey duque de la Palata (1681-1689), el gobierno colonial, sin conseguirlo, intentó restaurar la unidad económica bajo el centralismo de Lima. Sin embargo, sus esfuerzos no lograron su objetivo, y de modo definitivo todo otro intento a futuro fue desestimado (Lazo, 2001), al menos dentro del periodo monárquico que le quedaba a la dinastía Austria en España.

\section{Conclusión}

Las acciones del duque de la Palata estuvieron dirigidas a afianzar plenamente al virreinato peruano en la economía mundo de la época, y hacerle cumplir el papel que le fue fijado como 
proveedor de materias primas y consumidor de manufacturas europeas en base al mantenimiento de la matriz minería-comercio. En este caso, el duque fue un operador que implementó y desarrolló un programa para preservar el orden colonial en el Perú, conteniendo a los ejes económicos regionales paralelos que competían con Lima, los cuales constituían un peligro que amenazaba su estabilidad. Para ello, a partir de la elaboración de políticas macroeconómicas que se ajustaron a la doctrina económica mercantilista, la Palata apuntó a sostener la tambaleante reforma toledana con el propósito de hacerla más eficaz.

En este empeño, al no presentar una alternativa absolutamente distinta, basada en una economía manufacturera, la intervención de la Palata fracasa, al encontrar la férrea oposición de los grupos de poder locales discordes con sus reformas, ya que aquella perjudicaba sus operaciones empresariales. La autonomía alcanzada por los productores peruanos los pusieron en el umbral de convertir sus actividades en modernas, pero diversas condiciones lo impiden. Alcanzan las fases manufactureras de la modernidad, que en ese tiempo estaba en vigencia en la Europa más avanzada, pero, a diferencia de los manufactureros europeos, los peruanos nunca pudieron dar el salto. Y esto tuvo mucho que ver con el estatus colonial de la economía y sociedad peruana de entonces. En este sentido, el Perú estuvo inserto en los inicios de la modernidad, lejos, muy lejos del capitalismo, pero también lejos, muy lejos del sistema precapitalista.

Los efectos de las reformas de la Palata, si bien fueron importantes para la metrópoli, a largo plazo resultaron inmediatistas y tardías, reduciéndose a cambios pequeños y medianos que encontraron serios tropiezos en su aplicación. Los cambios producidos se encaminaron a hacer enmendaduras coyunturales, que en nada transformaron la estructura económica del sistema, el cual fue remozado con estas modificaciones, pero en esencia no detuvieron su socavamiento. Esto va a hacerse patente un siglo después, cuando ocurre la crisis del sistema colonial en el siglo XVIII.

\section{Agradecimientos}

En el proceso de preparación del presente artículo me favorecí grandemente con los consejos de Francisco Quiroz y Carlos Contreras, quienes desinteresadamente leyeron el presente manuscrito e hicieron útiles comentarios y críticas. Tengo también un agradecimiento especial para el recordado historiador Carlos Lazo García, quien fue una fuente inagotable de guía y apoyo para el proyecto original de este estudio.

\section{Archivos consultados}

\section{Archivo General de la Nación (AGN)}

Sección: Superior Gobierno

Colección Miscelánea

Colección Moreyra

\section{Biblioteca Nacional del Perú (BNP)}

Colección X

Colección Manuscritos

Colección Zegarra 


\section{Referencias bibliográficas}

Alonso Mola, María y Martínez Shaw, Carlos. (2000). Dignidad real. Madrid: Alianza.

Amadori, Arrigo. (2012). Fiscalidad y consenso en el virreinato del Perú, 1620-1650. América Latina en la historia económica, (2), 7-45.

Anderson, Perry (1979). El Estado absolutista. México D.F.: Siglo Veintiuno.

Andrien, Kenneth. (1985). Crisis and Decline: the Viceroyalty of Peru in the Seventeenth Century. Albuquerque: University of New Mexico Press.

Avilés, Miguel. (1986). El siglo XVII. Madrid: Nájera.

Bakewell, Peter. (1984). Los mineros de la montaña roja. El trabajo indio en Potosí, 1545-1650. Albuquerque: University of New Mexico Press.

Ballesteros, Tomás. (1752). De las ordenanzas del Perú dirigidas al rey por el virrey Melchor de Navarra. Lima: s/e.

Braudel, Fernand. (1984). Civilización material, economía y capitalismo, tomo 3. Madrid: Alianza.

Burkholder, Mark y Chandler, Dewit S. (1984). De la impotencia a la autoridad. La corona española y las Audiencias en América 1687-1808. México D.F.: Fondo de Cultura Económica.

Contreras, Carlos. (2002). El centralismo peruano en su perspectiva histórica. Lima: Instituto de Estudios Peruanos.

Contreras, Carlos y Zuloaga, Marina. (2014). Historia mínima del Perú. México D.F.: El Colegio de México.

Del Busto, José Antonio y Lohmann, Guillermo. (1994). Historia General del Perú: El Virreinato, tomo 5. Lima: Edit. Brasa.

Fernández Nadal, Carmen. (2013). Entre los mares del Norte y del Sur. La política diplomática de la monarquía hispánica con Inglaterra (1680-1688). Tiempos Modernos, (26), 1-26. https://bit.ly/3y36eo3

Ferreiro, Miguel. (5 de mayo de 2016). ¿Qué cobraban los soldados de un Tercio Español? El Reto Histórico. https://bit.ly/3ylukj5

Fisher, John. (1992). Relaciones económicas entre España y América hasta la independencia. Madrid: Mutualidad de la Agrupación de Propietarios de Fincas Rústicas de España (MAPFRE).

Flores Galindo, Alberto. (1977). Arequipa y el sur andino. Siglos XVIII-XX. Lima: Horizonte.

Garland, Alejandro. (1908). Estudio económico sobre los medios circulantes usados en el Perú. Lima: Imprenta La Industria.

Gil, Raquel, Lia Oliveto y Fernando Longhi. (2015). Mano de obra y fiscalidad a fin del siglo XVII: dispersión y variabilidad de la categoría yanacona en el sur andino. Boletín del Instituto de Historia Argentina y Americana, (43), 59-93.

Glave, Luis Miguel. (1989). Trajinantes: Caminos indígenas en la sociedad colonial, siglos XVI-XVII. Lima: Instituto de Apoyo Agrario.

Gonzáles Casasnovas, Ignacio. (2000). Las dudas de la corona. La política de repartimientos para la minería de Potosi (1680-1732). Madrid: Consejo Superior de Investigaciones Científicas.

Hanke, Lewis. (1976). Los virreyes españoles en América durante el gobierno de la Casa Austria, tomo 280. Madrid: Biblioteca de Autores Españoles.

Hobsbawm, Eric. (1988). En torno a los orígenes de la revolución industrial. Madrid: Siglo XXI.

Klein, Herbert. (1994). Fiscalidad real y gastos de gobierno. El virreinato del Perú 1680-1809. Lima: Instituto de Estudios Peruanos.

Konetzke, Richard. (1972). América Latina II. La época colonial. México D. F.: Siglo Veintiuno.

Lazo García, Carlos (1975). Introducción al estudio de la Crónica de denuncia social virreinal (Tesis de bachiller). Universidad Nacional Mayor de San Marcos, Lima. 
Lazo García, Carlos (1992). Economía colonial y régimen monetario. Perú: siglos XVI-XIX. Lima: Banco Central de Reserva del Perú.

Lazo García, Carlos. (1997). Desajuste monetario de una crisis económica: una causa criminal memorable abierta a los funcionarios de la Casa de Moneda de Lima (1700-1730). Lima: Instituto de Investigaciones HistóricoSociales, Universidad Nacional Mayor de San Marcos.

Lazo García, Carlos (2001). Dos líneas de desarrollo feudal en el Perú colonial, en un contexto de economía mundial mercantilista y liberal (1550-1800). Ukupacha, (3-4), 176-183.

León Portocarrero, Pedro [El judío portugués]. (1958) [¿1615?]. Descripción del Virreinato del Perú. Crónica inédita de comienzos del siglo XVII. Rosario: Edición de Boleslao Lewin.

Lohmann Villena, Guillermo. (1964). Las defensas militares de Lima y Callao. Sevilla: Escuela de Estudios Hispano-Americanos.

López, Juan Luis. (1685). Discurso Jurídico, histórico-político en defensa de la jurisdicción real. Lima: s/n.

Lorente, Sebastián. (1870). Historia del Perú bajo la dinastía austríaca (1598-1700). París: Imp. de A. E.

Lynch, John. (1991). El siglo XVIII. Barcelona: Crítica.

Olivera, Pedro. (1905). La Política Económica de la Metrópoli. Lima: Imprenta La Industria.

La Palata, Melchor de Navarra, duque de. (1859) [1684]. Ordenanza general en favor de los indios y adoctrinamiento de ellos. Lima: S/e.

Palza Becerra, Héctor. (2008). Estado y Política en una economía globalizada liberal. Tecnocracia, profesionalización y agencia comercial. Perú, 1760-1800. Lima: S/e.

Rosas, Fernando. (1998). Crisis e historia: algunas consideraciones sobre la economía occidental en los siglos XIV y XVII. Sociedad y cambio en Occidente; siglos XI-XX. Lima: Universidad de Lima.

Sempat Assadourian, Carlos. (1982). El sistema de la economía colonial: Mercado interno, regiones y espacio económico. Lima: Instituto de Estudios Peruanos.

Suárez, Margarita. (1995). Comercio y fraude en el Perú colonial. Las estrategias mercantiles de un banquero. Lima: Instituto de Estudios Peruanos.

Tandeter, Enrique. (1992). Coacción y mercado. La minería de la plata en el Potosí colonial (1692-1826). Cusco: Centro Bartolomé de las Casas.

Tord, Javier y Carlos Lazo. (1981). Hacienda, comercio, fiscalidad y luchas sociales (Perú colonial). Lima: Pontificia Universidad Católica del Perú, Biblioteca Peruana de Historia, Economía y Sociedad.

Tord, Javier y Carlos Lazo. (1984). Economía y Sociedad. Dominio económico. Historia del Perú, tomo 4. Lima: Editorial Mejía Baca.

Vilar, Pierre. (1980). Crecimiento y desarrollo. Economía e historia. Reflexiones sobre el caso español. Barcelona: Ariel.

Presentado: 03/07/2020

Aceptado: 07/11/2020

Publicado online: 10/08/2021 